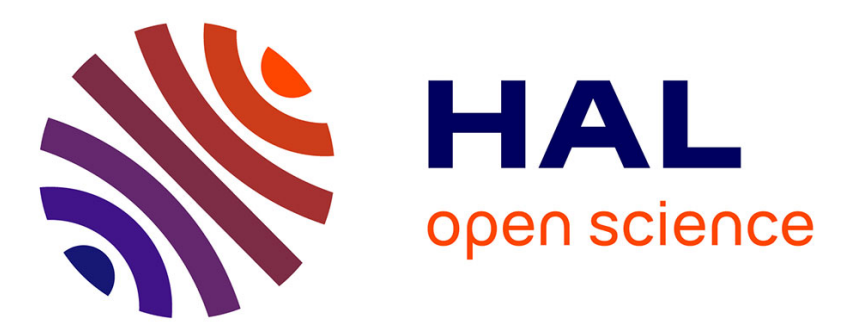

\title{
Dynamics of microseismicity and its relationship with the active structures in the western Corinth Rift (Greece)
}

Clara Duverger, Sophie Lambotte, Pascal Bernard, H. Lyon-Caen, Anne Deschamps, A. Nercessian

\section{To cite this version:}

Clara Duverger, Sophie Lambotte, Pascal Bernard, H. Lyon-Caen, Anne Deschamps, et al.. Dynamics of microseismicity and its relationship with the active structures in the western Corinth Rift (Greece). Geophysical Journal International, 2018, 215 (1), pp.196 - 221. 10.1093/gji/ggy264 . hal-01845974

\section{HAL Id: hal-01845974 https://hal.science/hal-01845974}

Submitted on 22 Jan 2019

HAL is a multi-disciplinary open access archive for the deposit and dissemination of scientific research documents, whether they are published or not. The documents may come from teaching and research institutions in France or abroad, or from public or private research centers.
L'archive ouverte pluridisciplinaire HAL, est destinée au dépôt et à la diffusion de documents scientifiques de niveau recherche, publiés ou non, émanant des établissements d'enseignement et de recherche français ou étrangers, des laboratoires publics ou privés. 


\title{
Dynamics of microseismicity and its relationship with the active structures in the western Corinth Rift (Greece)
}

\author{
C. Duverger, ${ }^{1}$ S. Lambotte,${ }^{2}$ P. Bernard, ${ }^{1}$ H. Lyon-Caen, ${ }^{3}$ A. Deschamps ${ }^{4}$ and \\ A. Nercessian ${ }^{1}$ \\ ${ }^{1}$ Institut de Physique du Globe de Paris, Sorbonne Paris Cité, Université Paris Diderot, CNRS, 75005 Paris, France. E-mail: clara.duverger.pro@gmail.com \\ ${ }^{2}$ Institut de Physique du Globe de Strasbourg, UMR7516, Université de Strasbourg, EOST/CNRS, 67000 Strasbourg, France \\ ${ }^{3}$ Laboratoire de Géologie, École Normale Supérieure de Paris/CNRS UMR8538, PSL Research University, 75005 Paris, France \\ ${ }^{4}$ Université Côte d'Azur, CNRS, Observatoire de la Côte d'Azur, IRD, Géoazur, 06560 Valbonne Sophia Antipolis, France
}

Accepted 2018 June 28. Received 2018 February 9; in original form 2018 June 26

\section{S UMMAR Y}

We analyse the complete earthquake archive of the western Corinth Rift using both crosscorrelations between pairs of event waveforms and accurate differential traveltimes observed at common stations, in order to identify small-scale fault structures at depth. The waveform database was generated by the dense Corinth Rift Laboratory network and includes about 205000 events between 2000 and 2015. Half of them are accurately relocated using doubledifference techniques. The novelty of this relocated catalogue is the integration of the recent westernmost earthquakes due to the extension of the network in 2010 to the western extremity of the Corinth Rift and the consideration of the whole database over more than $15 \mathrm{yr}$. The total relocated seismicity exhibits well-defined clusters at the root of the main normal faults mainly between 5 and $10 \mathrm{~km}$ depth in the middle of the gulf and illuminates thin active structure planes dipping north about $20^{\circ}$ under the northern coast. Some seismicity is observed in the footwall of the main active faults, along the West and East Helike faults. We also built a multiplet database based on waveform similarity taking into account cross-correlation coefficients weighted by signal-to-noise ratios. Short-term multiplets are concentrated in the middle of the gulf along the Kamarai fault system, in a $1-2 \mathrm{~km}$ thick layer at $6-8 \mathrm{~km}$ depth, interpreted as a highly fractured geological layer. They are often associated to slow seismic migration velocities occurring in this zone during strong swarm episodes and are thus likely to be triggered by pore pressure variations. On the other hand, most long-term and regular multiplets are located deeper (7$10 \mathrm{~km}$ ), under the northern coast, within a layer less than $0.3 \mathrm{~km}$ thick. They occur at the border of nearly planar structures with low seismicity rate, which we identify as fault planes, and they may be explained by aseismic slip on the fault surface around them. This supports the existence of an immature structure growing downdip towards the north at the base of the active geological layer, which possibly connects to the ductile middle crust around $15 \mathrm{~km}$ depth, as suggested by the occurrence of deeper events in the continuity of the 1995-fault plane. The different migration velocities (from $0.05 \mathrm{~km} \mathrm{~d}^{-1}$ to several $\mathrm{km} \mathrm{d}^{-1}$ ) highlighted during the western 2014-swarms indicate that both pore pressure and creep diffusion are operating in the fault zone. The fast migrations observed in the Psathopyrgos fault zone, where a slow slip event was detected by dilatometers in 2002, compare with that for creeping faults. To the west, from spatial distribution of events, we show that the Rion-Patras fault connecting the western extremity of the Corinth Rift fault system to the Patras Rift, is dipping around $60^{\circ}$ north-west with a rake angle of $-115^{\circ}$. Finally, we identified two new areas within the central active zone which may correspond to large scale, locked asperities on active fault surfaces, similar in size to the main asperity broken during the $1995, M_{\mathrm{W}} 6.3$, Aigion earthquake.

Key words: Europe; Transient deformation; Earthquake dynamics; Seismicity and tectonics. 


\section{INTRODUCTION}

The Corinth Rift has been studied for more than two decades, based on geological (e.g. Armijo et al. 1996), geodetic (e.g. Briole et al. 2000; Avallone et al. 2004) and seismological observations (e.g. Latorre et al. 2004; Bernard et al. 2006; Pacchiani \& Lyon-Caen 2010; Sokos et al. 2012; Lambotte et al. 2014; Kapetanidis et al. 2015; Mesimeri et al. 2017). It is an active asymmetric graben extending E-W over $100 \mathrm{~km}$, where south coast uplifts of several millimetres per year over at least the last $0.3 \mathrm{Myr}$ (e.g. Vita-Finzi 1993; Armijo et al. 1996; Rohais 2007). The fault system (Fig. 1) is mainly composed of onshore antithetic normal faults, with the main active faults cropping out on the southern coast and dipping north at $40^{\circ}-60^{\circ}$. Some active offshore faults have also been identified in the middle of the gulf (e.g. Stefanos et al. 2002; Moretti et al. 2003; Bell et al. 2008; Beckers et al. 2015). On the northern coast, the south dipping normal faults have been less extensively studied. Currently, the north-south extension of the rift is inhomogeneous, with a high extension rate of around $15 \mathrm{~mm} \mathrm{yr}^{-1}$ in the western part and $10 \mathrm{~mm} \mathrm{yr}^{-1}$ in the eastern part (Briole et al. 2000; Avallone et al. 2004). The Corinth Rift has one of the highest strain rates in the world (about $10^{-15} \mathrm{~s}^{-1}$ ). This deformation is the consequence of the backarc extension due to the Hellenic subduction in the south and the westward propagation of the North Anatolian Fault (Armijo et al.1996). In the history of the rift activity, the older inland normal faults have been progressively deactivated and its deformation has been translated northwards, presently centreed in the middle of the gulf. The western tip of the gulf has shown evidence of strike-slip motion (Rigo et al. 1996; Beckers et al. 2015).

From a geological point of view, the first $5-10 \mathrm{~km}$ of the crust is made of the Hellenide nappe stack, composed of a succession of five different carbonate nappes. Three of them outcrop in the western and central Corinth Rift (Fig. 1). These geological structures are inherited from the past east-west convergence during the Miocene. They may have influenced the sedimentation and the fault segmentation (Ghisetti \& Vezzani 2004) and may play a role in the lateral variability of the seismicity distribution (Gautier et al. 2006; Lambotte et al. 2014; Duverger et al. 2015).

The Corinth Rift has been shaken by a few destructive $M>$ 6 earthquakes per century, making it one of the most seismically active regions in Europe. For instance, in the 19th century, two historical earthquakes that occurred in 1817 and 1888 have been associated to the Aigion fault and one in 1861 to the Helike fault (Albini et al. 2017; Fig. 1). However, some large recent earthquakes of the region do not seem to be associated to one of the main fault planes visible at the surface. This is especially the case for the major earthquake $M_{\mathrm{W}} 6.3$ in 1995, which occurred on a low-angle north dipping blind fault and caused severe damages in the city of Aigion (Bernard et al. 1997). The analysis of the doublet of magnitude $M_{\mathrm{W}}>5$ earthquakes in 2010 emphasizes a link with shallow steep dipping fault structures, but has not been associated to any known major normal faults (Sokos et al. 2012). The fault plane extensions at depth are not well constrained or sometimes totally unknown, so that linking an earthquake to a fault remains complicated even nowadays.

The microseismic activity follows a swarm organization, with alternation of intensive crisis and more quiescent periods. The controlling factor of these seismic swarms is still not well understood, but some crises have been explained by fluid circulations or pore pressure diffusions (Bourouis \& Cornet 2009; Pacchiani \& LyonCaen 2010; Duverger et al. 2015). The microseismicity is mainly concentrated into a $3 \mathrm{~km}$ thick layer below the gulf, slightly dipping north at very low angle (15 ; e.g. Rigo et al. 1996; Lyon-Caen et al. 2004; Gautier et al. 2006), which has fed a debate on the presence of either a large-scale detachment at 6-9 km depth acting as a shear zone (Rigo et al. 1996; Bernard et al. 2006), or a brittle-ductile transition zone (Hatzfeld et al. 2000). The detachment has been interpreted as an inherited crustal-scale detachment (Jolivet et al. 2010) or as an immature blind detachment (Lambotte et al. 2014). Whatever the case, the observed normal faults at the surface seem to root into this layer, since almost no seismicity is observed below $9 \mathrm{~km}$ depth beneath this layer.

Using more than 20000 events of moment magnitudes ranging from 1 to 4 , the objectives of this paper are (1) to present new insights into the westernmost deep structures and their relationships with the faults observed at the surface, (2) to characterize the spatio-temporal evolution of the microseismicity and (3) to identify the interactions between seismic and aseismic mechanisms. With this aim in mind, we perform waveform cross-correlations and a double-difference relocation coupled with a multiplet classification to identify small-scale structures within the microseismicity and to characterize their reactivation through years. Thanks to the westward extension of the seismological network, we extend the study of Lambotte et al. (2014) to the westernmost part of the Corinth Rift and perform an homogeneous and detailed analysis of the 2000 2015 data. Recently, Mesimeri et al. (2017) presented a relocation of about 30000 events in the entire Corinth Rift from 2008 to 2014 using the regional HUSN catalogue. In our paper, we present a relocation of the whole $16 \mathrm{yr}$ available data using the dense CRL local network and a more complete catalogue (completeness magnitude $M_{\mathrm{W}} \sim 1.2$ ). In addition, this large catalogue allows us to precisely characterize the temporal evolution of the seismicity and investigate its dynamic implications for the deformation in relationship with the detailed structures of the fault system and for the seismic hazard.

After a description of the local seismic network and data sets used, we explain the different steps of the relocation process and the multiplet extraction. Then we present the high-resolution images of the global relocated microseismicity, describing the fault geometries at depth. We statistically analyse the spatio-temporal evolution of the multiplets to propose different mechanisms or stress responses across the rift. We finally discuss the active fault structures in terms of possible mechanical sources and seismic hazard.

\section{DATA AND METHODS}

We take advantage of the dense distribution of recorded events within the western Corinth Rift over the last two decades to obtain a high-resolution image of the microseismicity at depth. We proceed in three main steps: (1) cross-correlation of waveforms, (2) relocation of the seismicity using a double-difference technique and (3) identification of multiplets by hierarchical clustering. Here, we describe the data set used and the different stages of the processes.

\subsection{Seismic network and waveform data set}

We use the entire seismic archive, $16 \mathrm{yr}$ of data recorded by the CRL network (Corinth Rift Laboratory, 2013), from spring 2000 to winter 2015. This database includes around 225000 events, slightly less than 14 million digital waveforms $(800 \mathrm{~Gb})$ recorded at about 15 different permanent or temporary stations on an average. The first permanent stations of the CRL network have been installed in 2000 in the western part of the rift around the city of Aigion by a French CNRS team. Between 2000 and 2009, the network 


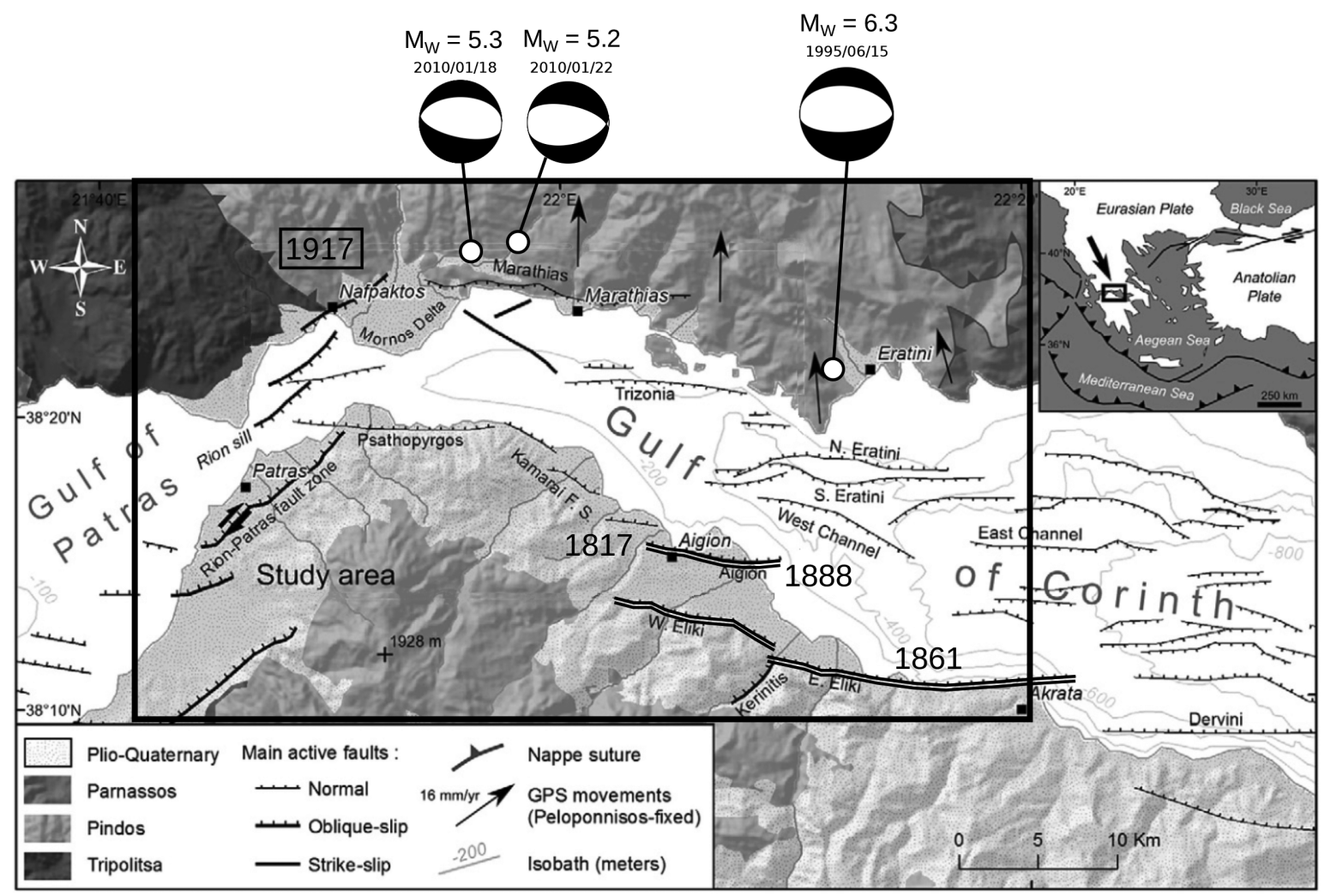

Figure 1. Tectonic map of the central and western part of the Corinth Rift. Onshore active faults are from Ford et al. (2009, 2013); Palyvos et al. (2005, 2008), main offshore faults are from Flotté et al. (2005); Bell et al. (2009); Taylor et al. (2011); Beckers et al. (2015). Isobaths are from Bell et al. (2008) and GPS measurements are from Avallone et al. (2004). Epicentres and focal mechanisms of the two $M_{\mathrm{W}} 5$ earthquakes are from Sokos et al. (2012) and from Bernard et al. (1997) for the $M_{\mathrm{W}} 6.3$ Aigion earthquake. Historical earthquakes of magnitude $M \geq 6$ affecting faults in the study area (double thick lines) are mentioned by dates (Albini et al. 2017). The distribution of the onshore Hellenide nappes and the Plio-Pleistocene sediments are drawn and described in the legend. The insert shows the Hellenic subduction in the south and the dextral strike-slip North Anatolian Fault. Modified from Beckers et al. (2015).

covers a $30 \mathrm{~km} \times 30 \mathrm{~km}$ area with 11 permanent stations recording at $125 \mathrm{~Hz}$, equipped with three-component seismometers (ALIK, AGEO, AIOA, DIMT, ELE, KOU, PANR, PSAR, PYRG, TEME and TRIZ). From 2010, four new three-component velocimeters recording at $100 \mathrm{~Hz}$ have been installed further west to especially monitor the activity of Psathopyrgos zone (AGRP, MALA, ROD3 and ZIRI). Some temporary stations (FIL, MYL and HELI) have been installed to monitor aftershock activity in 2010 on the northern coast and a large swarm activity in 2013 on the southern coast. In 2013, an antenna with seven broad-band stations has been deployed in Magoula (MG0). Nowadays, the CRL network covers a $60 \mathrm{~km} \times$ $40 \mathrm{~km}$ area (Fig. 2).

The CRLNET also includes seven stations recording at $100 \mathrm{~Hz}$ equipped with broad-band seismometers operated by the University of Athens (KALE and LAKA) and the University of Patras (ANX, EFP, SERG, UPR and VVK). Since 2010 all stations are recording at $100 \mathrm{~Hz}$, we thus down-sampled all previous records at $100 \mathrm{~Hz}$ to homogenize the database.

A post-trigger algorithm, based on an STA/LTA (short-term average/long-term average) ratio, is used to extract events from the continuous CRL records. It detects an event when more than three stations trigger at about the same time (within $3 \mathrm{~s}$ ) and picks the $P$ and $S$ phases when possible. Details on the detection and picking algorithms are available in Bourouis \& Cornet (2009). All events are automatically located using hypo71 software (Lee \& Lahr 1972), the 1-D velocity model of Rigo et al. (1996) and a $V_{\mathrm{P}} / V_{\mathrm{S}}$ ratio of 1.80 . The moment magnitude of events has been computed by spectral inversion of the seismograms (Satriano et al. 2016, https://gitlab.com/claudiodsf/sourcespec). Part of the data set (around 10 per cent) has been manually picked for specific studies. In this case, we prefer to use manual picks than automatic ones. Inaccuracies in the phase picks and errors in the initial model affect the hypocentre location errors. These latter vary from several hundreds metres to a few kilometres for events in the area covered by the network, with depths less well constrained than epicentres. The average standard errors for events outside the network can reach $5 \mathrm{~km}$ (Lambotte et al. 2014). These errors are many times larger than the spatial dimension of microearthquakes themselves. Indeed, magnitude 1-4 earthquakes have source dimension typically ranging from 10 to $1000 \mathrm{~m}$. Thus, studying the seismic hazard of active faults or the physical properties of these earthquakes is limited by these location uncertainties.

\subsection{Computation of waveform cross-correlations}

Here, we take advantage of the density of events recorded in the Corinth Rift. A common signal processing tool, the crosscorrelation is used both (1) to identify multiplets (a multiplet is a group of similar events, spatially close with identical focal mechanisms) and (2) to perform a relocation at local scale using the differential phase traveltimes between earthquakes (e.g. Waldhauser \& Schaff 2008). Such differential times are simultaneously inverted for estimating more precisely the distance between events (e.g. Got et al. 1994; Waldhauser \& Ellsworth 2000). 


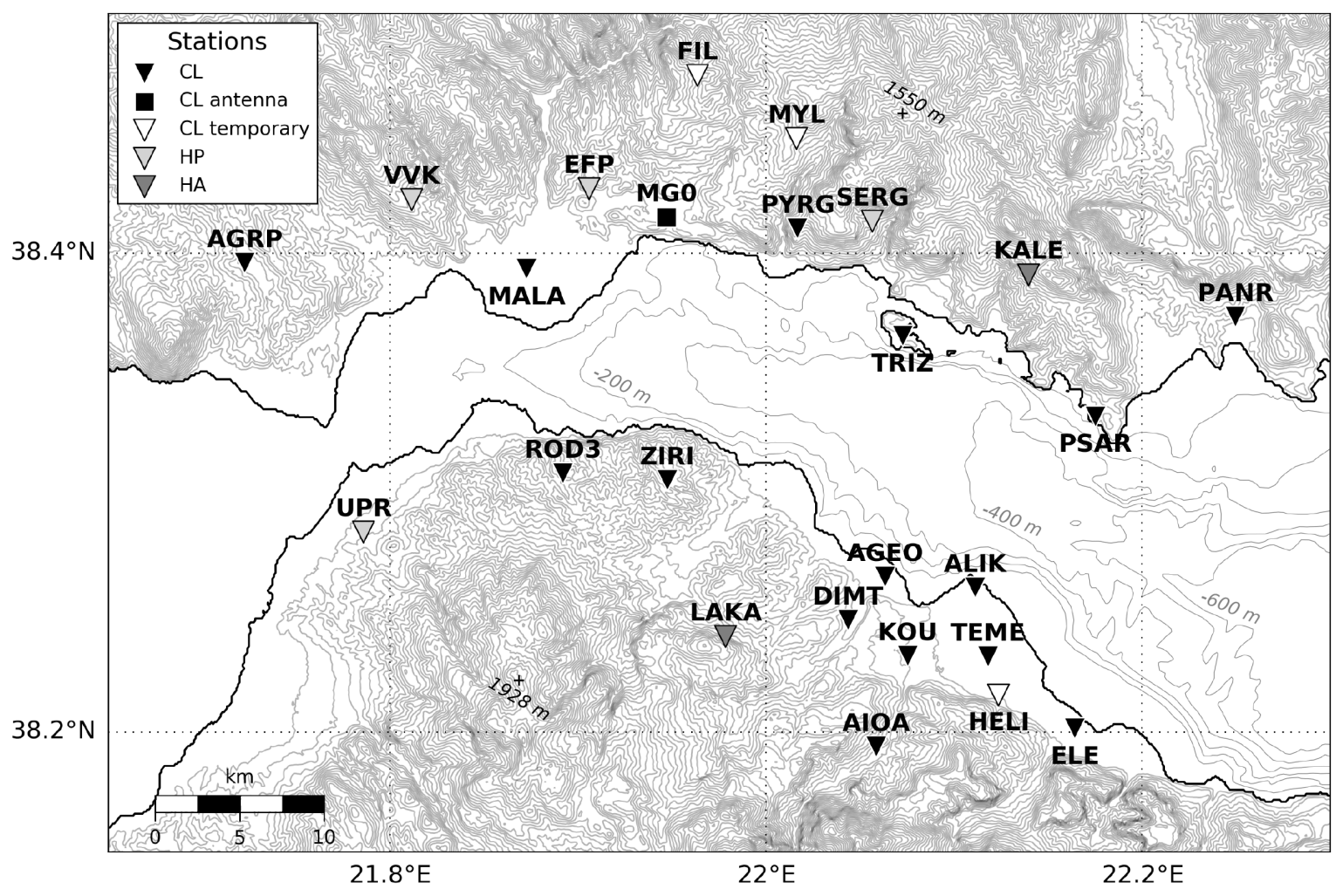

Figure 2. Map of the seismic stations used for the cross-correlations and the relocation. Black and white triangles (CL) are CNRS stations. Among them, the easternmost stations (ALIK, AGEO, AIOA, DIMT, ELE, KOU, PANR, PSAR, PYRG, TEME and TRIZ) started recording in 2000-2001 but ELE was removed in 2006 and KOU in 2011. FIL and MYL were temporary stations used in 2010 to record aftershocks of the two $M_{\mathrm{W}} 5$ earthquakes occurring in January 2010 on the northern coast (see Fig. 1). HELI is also a temporary station installed later in 2013 to record a large swarm occurring on the southern coast. ROD3 and ZIRI started recording in 2010, AGRP and MALA in 2012. MG0 (black square) is a CNRS antenna with seven broad-band seismometers set up in 2013. Light grey triangles (HP) are stations operated by the University of Patras (one of these stations, ANX, is off-map, $15 \mathrm{~km}$ just north of EFP). Dark grey triangles (HA) are stations from the University of Athens.

We use the time-domain cross-correlation to estimate the correlation coefficient $C_{C}$ which quantifies the similarity between two event waveforms recorded at a same station, and the time-shift $\tau$ which only corresponds to the traveltime difference if the initial alignment of the waveforms (zero lag) is at the corresponding phase arrival-time picks. Measuring traveltime differences and similarity coefficients by cross-correlation requires the choice of windows around phase arrival times for a pair of events. A battery of tests were conducted by Lambotte et al. (2014) to define correlation parameters that produce robust delay time measurements in an efficient manner for the Corinth Rift. Based on these tests and some readjustments linked to the evolution of the CRL network from 2010, we choose the following input parameters to run across the entire network.

Seismograms were filtered between 1.5 and $15 \mathrm{~Hz}$, instead of 3 and $20 \mathrm{~Hz}$ as in Lambotte et al. (2014), in order to allow for correlations between larger events $\left(M_{\mathrm{W}} \geq 3\right)$. According to Schaff \& Waldhauser (2005) who studied California data with a similar size problem as ours, filtering from 1.5 and $15 \mathrm{~Hz}$ increases the number of useful cross-correlation measurements reducing long-period instrument noise and less similar high frequencies. Correlation measurements were made on $1 \mathrm{~s}$ time-window lengths for the $P$-wave train and $2 \mathrm{~s}$ for the $S$-wave train, giving the opportunity to look for time-shifts up to $0.5 \mathrm{~s}$ for the $P$ - and $1 \mathrm{~s}$ for $S$-windows. The waveform windows begin at $0.3 \mathrm{~s}$ and $0.5 \mathrm{~s}$ before the $P$ - and $S$-pick arrival time, respectively. The $P$-windows were extracted from the vertical component and the $S$-windows were computed on the two horizontal components (east and north).

Cross-correlations are first computed at the time resolution of one sample $(0.01 \mathrm{~s})$ by aligning to the nearest sample, and finally at sub-sample time resolution using a polynomial fit in the vicinity of the peak of the cross-correlation function. This procedure enables the measurement of delays within millisecond precision and allows a reliable recovering for large delays (Schaff et al. 2004).

Numerically cross-correlating all events with each other in the case of more than 200000 events in the database, would be hardly feasible because of the size of the problem. To reduce it and for the purpose of the relocation procedure described in the Supplementary Information SA.1.2, we first divide the western Corinth Rift into 10 rectangles (Supplementary Information Fig. SA.2). The edges of boxes were chosen to lie as much as possible in regions of sparse seismicity and they overlap to ensure the spatial continuity in the seismicity.

In order to reduce the computational time, we do not crosscorrelate every event with every other event of the same area, but only event pairs less than $5 \mathrm{~km}$ apart. This radius was chosen taking into account the preliminary hypocentre location uncertainty and the known degradation of the waveform similarity with interevent separation distance. 
A total of 15 billion cross-correlation measurements ( $P$ waves on vertical component and $S$ waves on the two horizontal components) were performed. The computations were carried out on 10 nodes of the S-CAPAD ${ }^{1}$ cluster at a rate of about 30 million measurements per CPU hour.

\subsection{Double-difference relocation}

The resulting cross-correlation time-shifts are used to perform a high-precision relocation using double-differences of traveltimes (e.g. Got et al. 1994; Hauksson \& Shearer 2005; Waldhauser \& Schaff 2008), with HypoDD software (Waldhauser \& Ellsworth 2000). All the details about the data selection and weighting, the parameters for the inversion and the computational strategy are given in the Supporting Information SA.1. We also provide statistics on cross-correlation data in the Supporting Information SB, particularly the influence of signal-to-noise ratio (SNR; Supplementary Information Fig. SB.3), distance between events (Supplementary Information Fig. SB.4) and magnitude difference (Supplementary Information Fig. SB.5) on correlation measurements. Statistics on cross-correlations for $P$ - or $S$-wave windows and noise windows are also presented in Supplementary Information Figs SB.1 and SB.2, respectively.

In total, we relocate around 94000 events between 2000 and 2015 in the western Corinth Rift, from the 115000 selected ones which were recorded by four or more stations with at least six picked phases (Fig. 3). The new hypocentres show improved clustering both horizontally and vertically, creating a more focused picture of the complex distribution of seismicity. The HypoDD program does not estimate hypocentral errors directly and it was not feasible to carry out detailed error estimates here because of the large data set size. Nevertheless, some statistical tests using a bootstrap technique have previously been done on a smaller data set by Lambotte et al. (2014) to assess the relative relocation errors. According to the authors, which used the same relocation approach, the maximum relative relocation uncertainty is about $30 \mathrm{~m}$ in the centre of the rift where the density of events and the quantity of cross-correlations is high, and can reach few hundreds of metres at the edges where the network coverage is not sufficient.

\subsection{Classification of earthquake multiplets}

The resulting cross-correlation coefficients are then used to extract multiplets. Multiplets can provide additional information on the geometry of microstructures and are useful to characterize seismically active structures (e.g. Rietbrock et al. 1996; Pacchiani \& Lyon-Caen 2010). The whole methodology used to estimate a representative similarity coefficient $\left(S_{i j}\right)$ between two events, i and j, and define families of events is described in the Supplementary Information SA.2.

This $S_{i j}$ (Supplementary Information eq. SE.2) value ranges between 0 and 1 and is computed taking into account the crosscorrelation coefficients of the $P$ and the $S$ phase at each common station for a pair of events, weighted by the reduced SNRs of the waveforms (Supplementary Information eq. SE.1). The main particularity of our method is the use of SNRs of the body phases to weight the data. Basically, this weight increases nonlinearly from 0 to 1 with increasing SNR (Supplementary Information Fig. SA.1)

\footnotetext{
${ }^{1}$ Service de CAlcul PArallèle et de traitement de Données en sciences de la Terre
}

and depends on the pick type (automatic or manual). Data with SNR $<1.5$ are given a weight close to 0 , whereas data with SNR $>5$ are given a weight close to 1 . It appears to be a robust metric distance to classify events in multiplets. Their extraction is conducted by hierarchical clustering technique, which is detailed in the Supplementary Information SA.2.

Finally, we choose a similarity cut-off $S_{c}=0.8$ to define the multiplets and perform the structural analysis. The following description of families of events will then correspond to this threshold value. In this case, 70 per cent of the events of the CRL database are classified in multiplets, among those 66 per cent are in doublets.

In order to distinguish repeaters (a repeater is a group of events rupturing systematically a same asperity) from multiplets, we conduct a more detailed analysis with a stronger threshold. Among multiplets obtained with a 0.8 similarity cut-off, we cross-correlate their respective events with a $5 \mathrm{~s}$ waveform window encompassing the $P$ and the $S$ phase together. Indeed, repeater events should preserve the differential time between the $P$ and $S$ phase apart from the high waveform similarities. We then apply a higher similarity cut-off $S_{c}=0.9$ to construct repeaters.

\section{RESULTS}

After the relocation stage and the multiplet extraction, we obtain a high-precision image of the microseismicity at depth with the clustering of families of similar earthquakes. The Fig. $3 \mathrm{~b}$ presents the entire western Corinth Rift relocation map over 16 yr. We clearly observe that the seismicity is not distributed homogeneously across the gulf.

For the presentation of the results, we divided the studied area in three main sectors: the central zone ( $\mathrm{ZC})$, the western zone $(\mathrm{ZW})$ and the westernmost zone (ZM), which correspond to different seismic rate and spatial distribution of the microseismicity (Fig. 4a). We also introduced some acronyms for specific structures which will be described in this section: the North Eratini zone (NEZ), the Transition zone (TZ), the Trizonia Island zone (IZ), the AigionFassouleika fault zone (AFZ) and the Rion-Patras and Psathopyrgos fault zone (RPZ).

To describe these structures, we present eight vertical crosssections along the rift in the Fig. 5 and a dozen more in the Supplementary Information Fig. SC.1. The spatial extension of these cross-sections is shown in the Fig. $4 \mathrm{~b}$.

\subsection{Large-scale microseismicity patterns}

The absence of shallow events makes difficult to evaluate the geometry of faults at depth and to constrain their dips. However, analysing thinly clustered events in several cross-sections helps to define and interpret their geometry.

\subsubsection{The central part (ZC) versus the western part ( $\mathrm{ZW})$}

The western part (ZW) concentrates in average more than 10 events per day since 2000 and up to hundreds of events during swarms. Its seismicity is mainly located in the middle of the rift, offshore (Fig. 4), between 4 and $10 \mathrm{~km}$ depth, in a $1-2 \mathrm{~km}$ thick layer gently dipping north (sections P7 and P8, Figs 5c-d). Seismicity structures are complex and highly variable over short distances.

On the contrary, the ZC exhibits a lower seismicity rate with a seismic gap in the middle of the rift (Fig. 4 and section P4, Fig. 5a). Few small swarms are located under the northern coast at a depth 

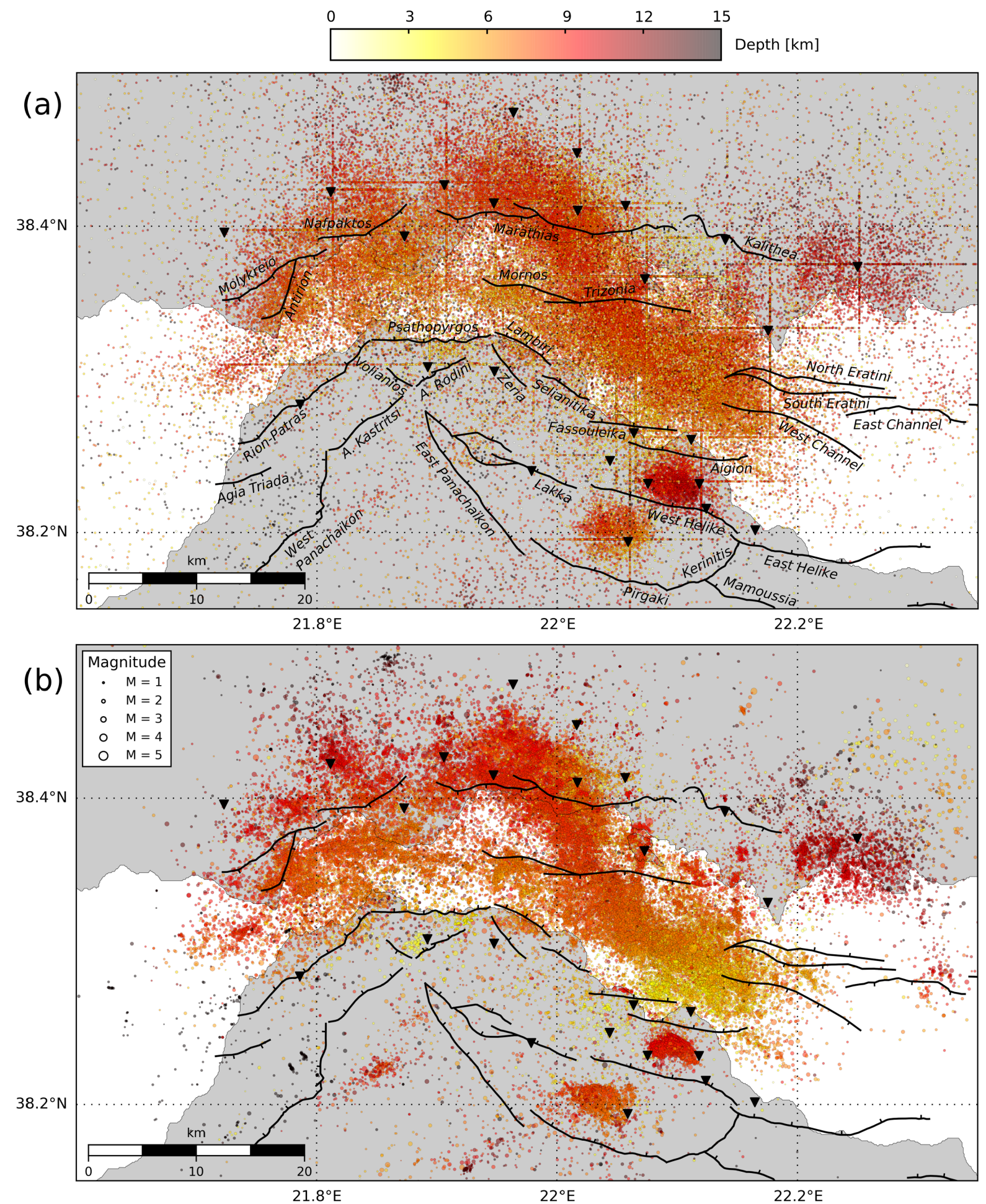

Figure 3. Maps of initial and relocated earthquakes. (a) Map of selected earthquakes for the relocation ( $\mathrm{n}=115000)$ from 2000 to 2015 , recorded by four or more stations (triangles) with at least six picked phases. These events are plotted at their original location obtained with hypo71. (b) Map of the relocated earthquakes $(\mathrm{n}=94000)$ computed with hypoDD. Dot size is proportional to the magnitude. Colours represent the depth of events. Black lines are the main normal faults of the region reported in Beckers (2015).

larger than $10 \mathrm{~km}$, in a less than $1 \mathrm{~km}$ thick layer, dipping $25^{\circ} \mathrm{N}$ (NEZ). The seismicity continues deeper further north, reaching almost $15 \mathrm{~km}$ depth. The fault system of ZC is shifted to the north compared to ZW, and its seismicity is deeper. This clear discontinuity in the seismic activity and the tectonic settings occurs over a small distance range $(5 \mathrm{~km})$ and will be described in more details as $\mathrm{TZ}$ in the Section 3.2.

The northwesternmost seismicity of the ZW mainly corresponds to the aftershock sequence after a doublet $\left(M_{\mathrm{W}} 5.3\right.$ and 5.2) occurring in 2010 January 18 and 2010 January 22 (zone 2AZ on 

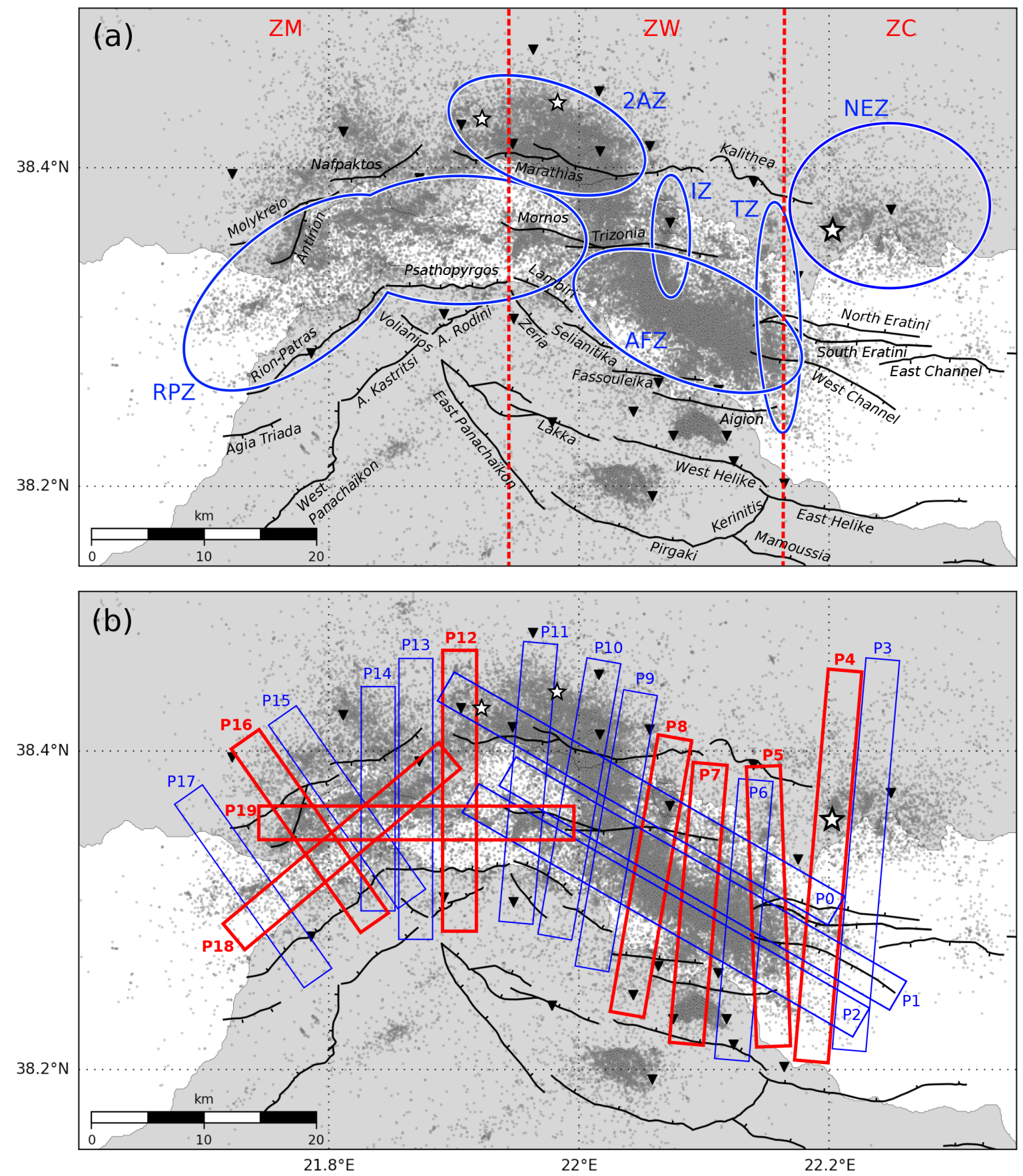

Figure 4. Main structures discussed and clusters delineated by the relocated seismicity. (a) Location of the different sectors (red dashed lines) and the main structures / clusters (blue ellipses) discussed in this section. Black lines are the main normal faults of the region reported in Beckers (2015). Grey dots are the relocated earthquakes. Black triangles indicate the seismic stations. White stars are the same $M_{\mathrm{W}} \geq 5$ earthquakes as those of Fig. 1. Initials are associated to names defined and used in the text (ZC, Central rift Zone; ZW, Western Zone; ZM, Westernmost Zone; NEZ, North Eratini Zone; TZ, Transition Zone; IZ, Trizonia Island Zone; AFZ, Aigion-Fasouleika Fault Zone; 2AZ, Aftershock Zone of the 2010 doublet; RPZ, Rion-Patras-Psathopyrgos Fault Zone). (b) Location of the cross-sections detailed in Fig. 5 for the thick red rectangular boxes, and in the Supplementary Information Fig. SC. 1 for the regular blue rectangular boxes.

the Fig. 4a), close to the Efpalio city (Sokos et al. 2012; Ganas et al. 2013). These events are the largest occurring in the western Corinth Rift since the $1995, M_{\mathrm{W}} 6.3$ Aigion earthquake. Hypocentres of the first and the second major events are respectively relocated at $\left(38.428^{\circ} \mathrm{N}, 21.890^{\circ}\right)$ at $11.5 \mathrm{~km}$ depth and $\left(38.441^{\circ}\right.$, $21.964^{\circ}$ ) at $10.5 \mathrm{~km}$ depth (Fig. $4 \mathrm{a}$ and Supplementary Information Fig. SC.1.1m). Our epicentre locations are in agreement with the previous estimates reported and compiled in the table 1 of Ganas et al. (2013). Our depth estimate of the January 18 th event is among the deepest proposed in other studies, which are ranging from 2 to $12 \mathrm{~km}$. The constant pattern retrieved over all studies is that the second main event is systematically shallower than the first one. According to Sokos et al. (2012), the rupture of the first event most likely occurred on a $55^{\circ}$ blind south-dipping nodal plane whereas its 

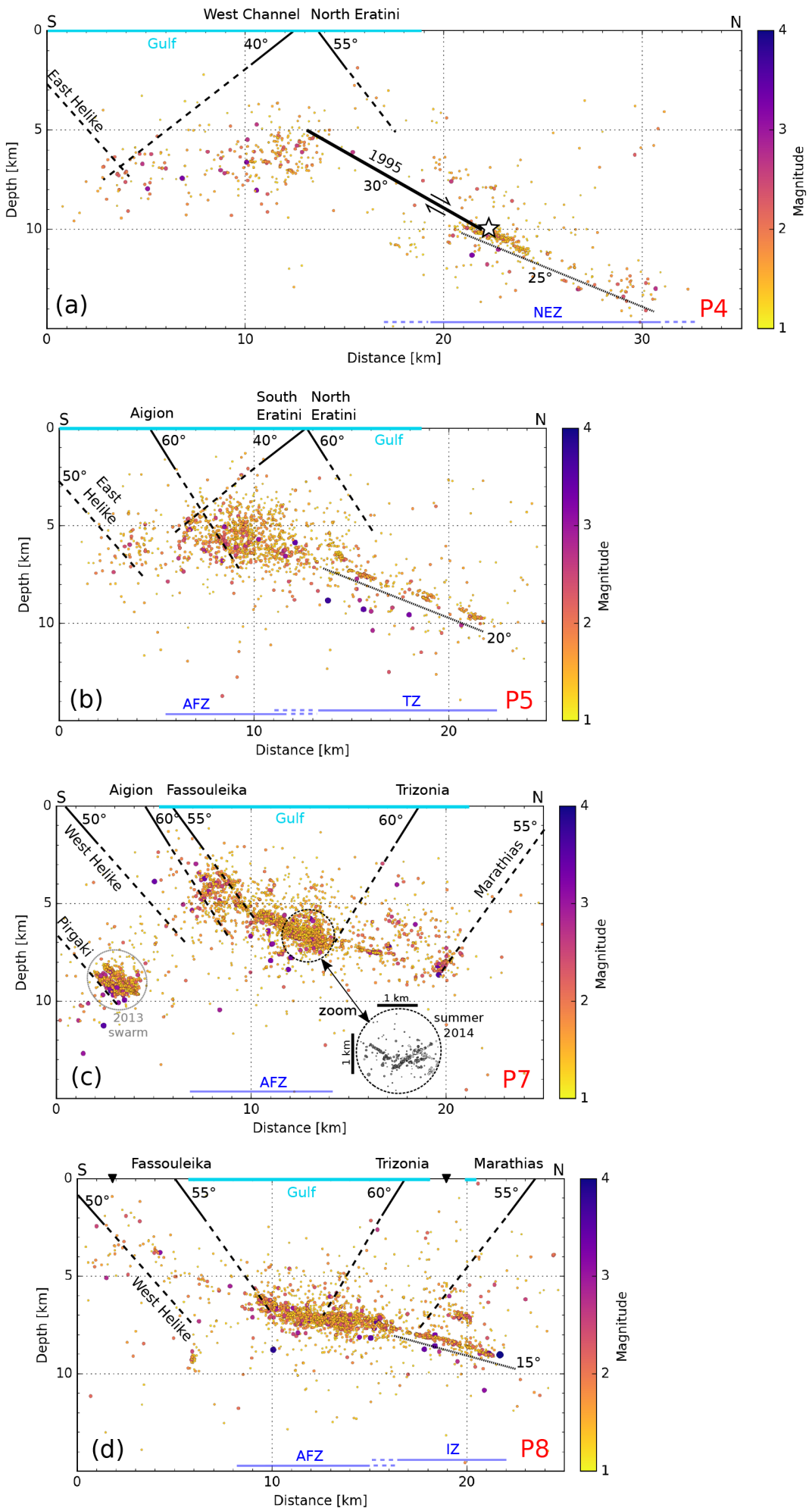

Figure 5. Vertical cross-sections along the western Corinth Rift. They are identified by thick red rectangles in Fig. $4 \mathrm{~b}$ and numbers. Bold black lines indicate the major onshore and offshore faults, with dashed thick lines for their extrapolation at depth. Light blue lines at the surface represent the offshore rift. Black triangles at the surface are the seismic stations. Dark blue lines at panel bottom represent the extension of zones defined in Fig.4a and described in the text. The colour scale and the dot size are proportional to the moment magnitude of events. The white star in (a) is the location of the $M_{\mathrm{W}} 6.31995$ earthquake, which ruptured a blind fault plane dipping $\sim 30^{\circ}$ and drawn in bold black line. The white star in (e) locates the $M_{\mathrm{W}} 5.3$ first major event of the doublet occurred in January 2010 (see Fig. 1). The zoom in (c) highlights some antithetic structures sub-parallel to the Trizonia fault plane, thanks to event clusters occurred in summer 2014. 

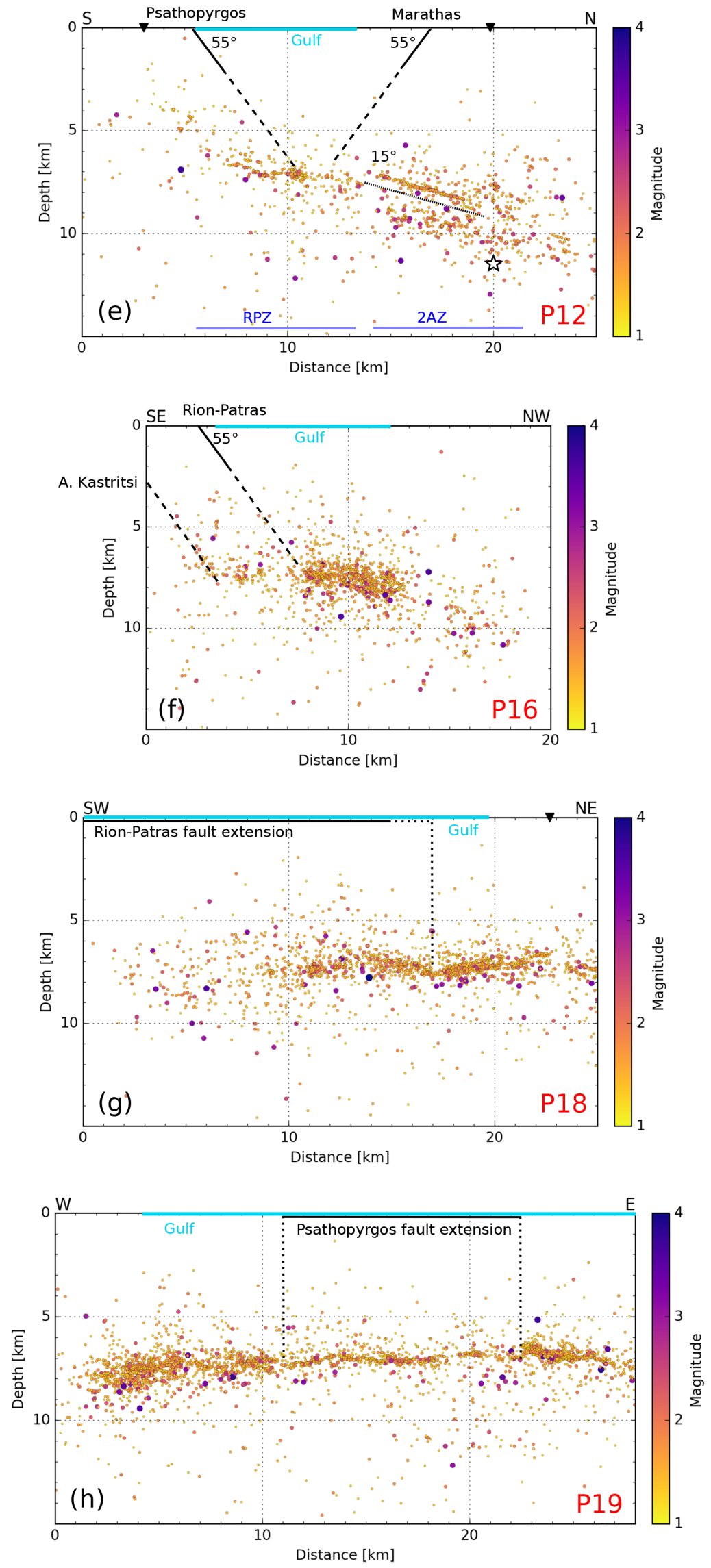

Figure 5. continued. 
aftershocks and the second event are connected to a north-dipping structure. Our global relocation does not bring additional clarification on these two sequences, nor did our further attempts to separately relocate them. The aftershocks are located between 5 and $9 \mathrm{~km}$ depth and it is hard to associate them with any structure at depth. Sokos et al. (2012) noted that aftershock clusters seem to be bounded by NE-SW strike-slip faults marked by earthquake strike-slip mechanisms at the western and eastern termination of the sequence. Our results support these observations as our relocated aftershocks stay confined in the same spatial area.

\subsubsection{The westernmost part (ZM) versus the western part ( $Z W)$}

In the westernmost part of the rift (ZM), the seismicity seems more clustered than in the ZW, where larger and laterally extended swarms are observed. This visual impression has to be tempered by the fact that no station was installed before 2010 in the ZM. If we only consider data above the completeness moment magnitude $M_{\mathrm{Wc}}=$ 1.2, from 2011 when the network covers the full area, we do not observe denser and larger spatially continuous swarms in the ZW than in the ZM, but sequences of small clusters detached from each other.

Clusters in the ZM are associated to the roots of the E-W Psathopyrgos fault and the NE-SW Rion-Patras fault, which follow the south coastline (Fig. 3). The lateral extension of clusters is also parallel to the two faults. The seismicity is mainly located between 5 and $10 \mathrm{~km}$ depth, in a really thin layer of about $200 \mathrm{~m}$ around Psathopyrgos fault (section P12, Fig. 5e), but in a $2 \mathrm{~km}$ thick layer around Rion-Patras fault (section P16, Fig. 5f), both gently dipping to the N-NW. The westernmost seismicity is a bit less well resolved at depth due to the network coverage, possibly explaining the larger thickness.

Moreover, we observe a seismic gap between the western part of the Marathias fault and the Mornos fault (Fig. 3), at the transition between the ZW and the ZM. Either the seismicity occurs north of the Marathias fault, under the northern coast and follows the coastline, or it occurs along a E-W line in the continuity of the mapped-extension of the Trizonia-Mornos faults, likely following the Psathopyrgos fault plane at depth (sections P12 and 19, Fig. 5).

\subsection{Fault zone structures}

\subsubsection{The North Eratini zone (NEZ), a deep structure}

The NEZ presents a specific seismic behaviour linked to the blind offshore fault which ruptured in 1995 (Bernard et al. 1997; Lambotte et al. 2014). The deep seismicity located at more than $10 \mathrm{~km}$ depth under the northern coast defines the downdip extension of this low-angle rupture plane dipping north $\sim 30^{\circ}$ (Bernard et al. 1997; section P4, Fig. 5a) . Moreover, according to Lambotte et al. (2014) the multiplets at the root of the fault show a similar dip around $30^{\circ}$. Either the microseismicity occurs directly on the deeper part of the blind fault plane, which then could be longer than previously proposed, or the microseismicity nucleates at the edges of the fault plane and delineates its depth termination.

\subsubsection{The transition zone (TZ), a structural boundary}

The ZC and the ZW are clearly separated by a thin structure oriented N-S shallowly dipping north and containing numerous clusters (Fig. 4). This discontinuity is not only visible in the seismicity distribution as already mentioned, but also in the geomorphological structures. This was already discussed by Lambotte et al. (2014), who identified a northward shift of the whole normal fault systems by $5-10 \mathrm{~km}$ at the transition between the Trizonia, the Aigion and the West Helike faults with the North Eratini, the South Eratini and the East Helike faults. The E-W fault extension of the LambiriFassouleika-Aigion fault system ends at the TZ. Moreover, Lambotte et al. (2014) noted that the structural boundary coincides with the transition between a narrow part of the rift with shallow bathymetry further west (the Channel and the Delphic Plateau), and an older, wider, deeper part of the rift further east (the Mornos Canyon leading to the Corinth abyssal plain; Heezen et al. 1966).

The integration of the 2008-2015 data to the 2000-2007 data set used in Lambotte et al. (2014) better highlights the discontinuity. The TZ is more clearly outlined by a north-south line of persistent clusters, which form a swelling of $\sim 2 \mathrm{~km}$ high (Supplementary Information Fig. SC.1.b and c). This seismic alignment also delineates the western boundary of the 1995 earthquake rupture plane (Bernard et al. 1997), where no or very little microseismicity has been recorded since. The origin and the nature of this structure is not yet well understood, but it has the same orientation as the Hellenic nappes (e.g Jolivet et al. 2010) inherited from the past convergence during the Miocene.

\subsubsection{The Trizonia Island zone (IZ), a second parallel structural boundary}

As for the TZ, the Trizonia Island zone (IZ) shows a north-south alignment of several clusters, with sparse seismicity on each side (Fig. 4). At depth, we observe that this deeper seismicity is contained in a thin layer, around $200 \mathrm{~m}$ thick, and is gently dipping north $15^{\circ}$ (section P8, Fig. 5d). On the contrary, the seismicity under the gulf is concentrated on a $1-2 \mathrm{~km}$ thick layer, almost flat, connecting to the root of the Fassouleika fault on the southern coast. The change from a thick flat layer under the gulf to the northern thinner layer of the IZ seems to coincide with the projection of Marathias fault plane at depth, dipping $55^{\circ}$. The IZ mimics the $\mathrm{TZ}$ in terms of seismicity alignment, but does not seem to be associated to a fault system discontinuity.

\subsubsection{The Aigion and Fassouleika fault zone (AFZ), a shallower activity}

In the AFZ, the microseismicity clearly outlines the Aigion fault and the Fassouleika fault up to 3-4 km depth (section P7, Fig. 5c). The dip of the structures is consistent with the one observed at the surface $\left(50^{\circ}-60^{\circ}\right)$, also constrained by the AIG10 borehole (Cornet et al. 2004) which is crossing the Aigion fault at $760 \mathrm{~m}$ in depth, and is consistent with the geometry and the fault plane solutions of multiplets (Godano et al. 2014; Duverger et al. 2015). The faults are rooting in the dense seismic layer, $1-2 \mathrm{~km}$ thick, almost horizontal. The fault system is better outlined by the microseismicity over the whole 2000-2015 period than it has been shown in previous studies over a restricted observational span (e.g. Lambotte et al. 2014). Some kilometre-long structures are observed in the seismic layer but with an antithetic direction (zoom in section P7, Fig. 5c), subparallel to the Trizonia fault plane extension. The Trizonia fault seems to mark the northern limit of the thick seismic layer, which further north becomes a really thinner layer aligned on a $15^{\circ}$ dip plane as for the TZ and the IZ (section P7, Fig. 5c). 


\subsubsection{The Rion-Patras and Psathopyrgos fault zone (RPZ), a connection between two gulfs}

We have seen that the microseismicity in the ZM of the Corinth Rift could appear to be less dense, but this is actually the effect of the late widening of the network. The two main normal faults on the southern coast of the rift, the Rion-Patras and the Psathopyrgos faults, meet at the surface with a high angle change in strike. The observed microseismicity is mainly following these structures. The relocated clusters are aligned on an E-W straight line parallel to the Psathopyrgos fault, in the middle of the rift and then turn parallel to the Rion-Patras fault, following the coast line at $\mathrm{N} 45^{\circ} \mathrm{E}$. We also observe some seismicity under the Rion-Patras fault, in its footwall, which is possibly connected to the inland A. Kastrisi fault or related to the Hellenic nappe stack (sections P15 and P16, Supplementary Information Fig. SC.1).

The sections P18 and P19 of the Fig. 5, which are parallel to the Psathopyrgos and the Rion-Patras, respectively, present nice pictures of the seismicity occurring along the two fault planes. The known surface extension of the Psathopyrgos and the Rion-Patras faults are reported on the cross-sections. The seismicity is mainly located around $7 \mathrm{~km}$ depth in a layer varying from hundred-metrethick to kilometre-thick. The location of the southwesternmost seismicity is not well defined due to the poor seismic network coverage there, explaining the large dispersion in depth in section P18, (Fig. 5g). We note a change in the seismicity at $17 \mathrm{~km}$ (horizontal axis) on the same cross-section which possibly images the junction between the two faults. The projection of this change at the surface does not fall on the Rion-Patras fault trace. However, in section P19, (Fig. 5h), we clearly identify the seismicity extending along the Psathopyrgos fault which precisely corresponds with its mapped surface extension. In this section, the seismicity is concentrated in a very thin flat layer, $100 \mathrm{~m}$ thick, at $7 \mathrm{~km}$ depth and includes clusters. Further west and further east, the seismicity gets more scattered.

\subsection{Spatio-temporal evolutions}

\subsubsection{Migration velocity during swarm activity}

In the western Corinth Rift, during swarms, migrations of microseismicity have already been observed and some of them have been analysed in details. For instance, in 2001, the spatio-temporal evolution of the Agios-Ioannis earthquake swarm was modelled by Pacchiani \& Lyon-Caen (2010) assuming a fluid-driven seismicity migrating upwards at a velocity of $0.02 \mathrm{~km} \mathrm{~d}^{-1}$. The $2003-2004$ seismic crisis occurring along the Aigion and Fassouleika faults was associated to a hydroshear process caused by pore pressure migration (Duverger et al. 2015) at about $0.05 \mathrm{~km} \mathrm{~d}^{-1}$. In 2006-2007, another swarm with westward migration (Lambotte et al. 2014) occurred in the middle of the gulf, close to Selianitika and Lambiri faults.

Here, we present some results on two large swarms which occurred in 2014, one in the ZM along the Psathopyrgos and RionPatras faults, and another in the middle of the gulf along the Kamarai fault system. During these seismic crises, a broad variety of migration velocities is observed. All migration velocities mentioned in the following text are projected along the E-W axis, which is the main migration direction at first order. True migration velocities are then equal or larger than the ones discussed here.

First, we describe the westernmost 2014-swarm. In July, we observe a first slow westward migration of the microseismicity at about $0.08 \mathrm{~km} \mathrm{~d}^{-1}$, which started at the western end of the Psathopyrgos fault (Fig. 6). A second shallower eastward migration at a velocity of $0.3 \mathrm{~km} \mathrm{~d}^{-1}$ occurred from mid-August along the Psathopyrgos fault. From mid-September, a new, faster, bilateral migration started close to the junction between the Rion-Patras fault and the Psathopyrgos fault, with several magnitude $M_{\mathrm{W}} 3$ events. The eastward velocity reaches $3 \mathrm{~km} \mathrm{~d}^{-1}$ along the Psathopyrgos fault. Both westward and eastward velocities of this bilateral migration are of the order of a few $\mathrm{km} \mathrm{d}^{-1}$. Contrary to previous swarm activities in this region, the two main faults seem to be connected and are activated as a continuous fault system during this crisis.

Second, we are interested in the 2014-swarm which developed from June to December along the Kamarai fault system (Fig. 7). It started relatively deep, at $7-8 \mathrm{~km}$ depth, just after the 2014 June $8 M_{\mathrm{W}} 4$.1. This event is either located at the western end of the Fassouleika fault, or on the Trizonia fault, the focal mechanism being compatible with both. Looking at the vertical cross-section (Fig. 7b), the event is relocated in the continuity of the Trizonia fault extension at depth, leading us to favour a fault plane dipping south. Hypocentres of early aftershocks rapidly migrate to the north-east, over $3 \mathrm{~km}$ away from the main shock in $10 \mathrm{~min}$. Knowing that a magnitude 4 event has a typical rupture dimension of about $1 \mathrm{~km}$, this denotes a strong post-seismic effect. Then, the seismicity front migrated eastwards at $1 \mathrm{~km} \mathrm{~d}^{-1}$ for 2 more kilometres (Fig. 7e), while another slower migration at about $0.05 \mathrm{~km} \mathrm{~d}^{-1}$ continued during almost 3 months (Fig. 7d). Two different classes of migration velocities, slow and fast, are observed there and this variability will be more discussed in Section 4.1.2. During the slow migration, the seismic activity jumped eastwards, with events a bit shallower (6 km depth) to finally come back deeper and fill in the spared area. From mid-August, another westward migration at $0.05 \mathrm{~km}$ $\mathrm{d}^{-1}$ occurred along the Fassouleika fault extension and lasted more than 2 months. The seismic rate slowed down at the end of October, just before the occurrence of the 2014 November $7 M_{\mathrm{W}} 4.7$ event located at $5.5 \mathrm{~km}$ depth, which triggered an intense and shallower swarm on the Aigion fault (Figs 7a, c and d). Regular aftershocks are detected within hours on the shallow part (around $4 \mathrm{~km}$ depth) of the Aigion fault, with a lateral extension of about $8 \mathrm{~km}$. An eastward migration of the aftershocks is observed at a velocity of $0.6 \mathrm{~km} \mathrm{~d}^{-1}$ (Fig. 7f). When the activity on this fault slows down, the Fassouleika fault remains active with the same westward migration at a velocity of $0.05 \mathrm{~km} \mathrm{~d}^{-1}$. The two faults seem to play alternatively and independently.

The seismicity from June to November starts below $7.5 \mathrm{~km}$ depth and migrates progressively upwards until $6.5 \mathrm{~km}$ depth, before the activation of the more superficial crisis in November, ranging from 3.5 to $7.0 \mathrm{~km}$ depth.

\subsubsection{Relationship between shallow and deep seismicity}

The last 2014-swarm showed that the shallowest activity along the Aigion-Fassouleika fault system occurred following a relatively shallow $M_{\mathrm{W}} 4.7$ earthquake. Globally, over the 2000-2015 period in the Corinth Rift, events shallower than $6 \mathrm{~km}$ depth mainly occur in conjunction with the main swarm activities (Fig. 8). We do not observe specific shift in time or pattern of the high activity of shallow events compared to deeper events or major events. We also often note that main shocks triggered shallower aftershocks either instantaneously or with a migration pattern as seen previously. Moreover, we observe that the largest events $\left(M_{\mathrm{W}}>3\right)$ are localized deeper than the smaller magnitude (Supplementary Information Fig. SC.2). At first glance, this characteristic might be 


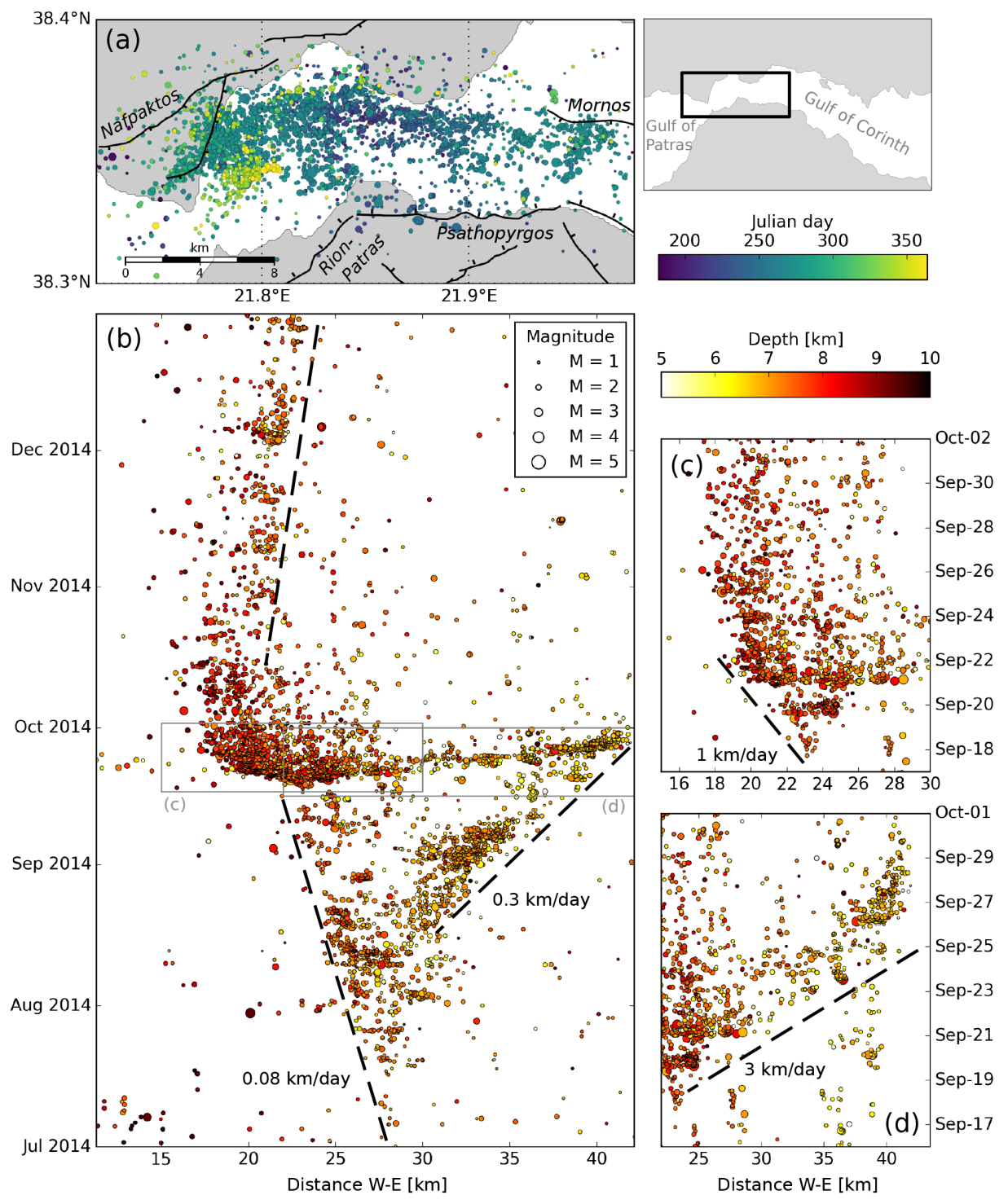

Figure 6. Seismic migration velocities during the westernmost (ZM) swarm in 2014. (a) Map of the seismicity migration along the Psathopyrgos, Nafpaktos and Rion-Patras faults. The longitude $21.6^{\circ}$ is $0 \mathrm{~km}$ distance. The black lines are the main normal faults. The colourbar represents the time in Julian days of 2014. (b) Temporal evolution of the microseismicity along the longitude. The circle size is proportional to the event magnitude. (c) and (d) are zooms in

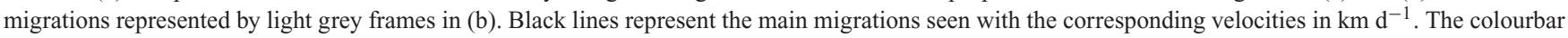
represents the event depth.

due to the relocation process, in that $M_{\mathrm{W}} \sim 3$ events have a different frequency content than smaller events, thus are possibly less well correlated to them. However, relative location errors on the largest events are very similar to those of their neighbour events in the swarm, so we are confident in their relocated position. This observation suggests that faults are larger in the deeper part of the thick layer than in its more active central part. We suggest different interpretations: (1) this could reflect a geological heterogeneity or a lithological variation, with for instance a brittle or finely stratified limestone in upper part against a massive limestone in the deeper part; (2) it could be a sign of a mechanical evolution of the layer, with an intense fracturing of the medium linked to the rooting normal faults. The shear stress layer would be more fractured with smaller structures in the upper part than in the deeper part, where the fault planes are better preserved with a higher magnitude potential.

\subsubsection{Long-term and short-term multiplets and repeaters}

We map all multiplets composed by at least 10 relocated events, which represents more than 1000 families (Fig. 9). The first observation is that multiplets are localized in dense seismic area (Supplementary Information Fig. SC.1). The lower number of multiplets found in the ZM is likely related to the recent installation of seismic stations there.

Some of the multiplets are clustered in time, others last several years (Fig. 9b). Godano et al. (2015) noted that multiplets with a regular or persistent activity are located under or close to the northern coast of the Corinth Gulf, at the root of the 1995-fault. We therefore analyse the temporal activity of the major multiplets in order to check these observations over the whole time period (16 yr). We classified the multiplets into two groups: long-term and short-term. The long-term multiplets are regularly activated throughout the observational period or for at least several years. 

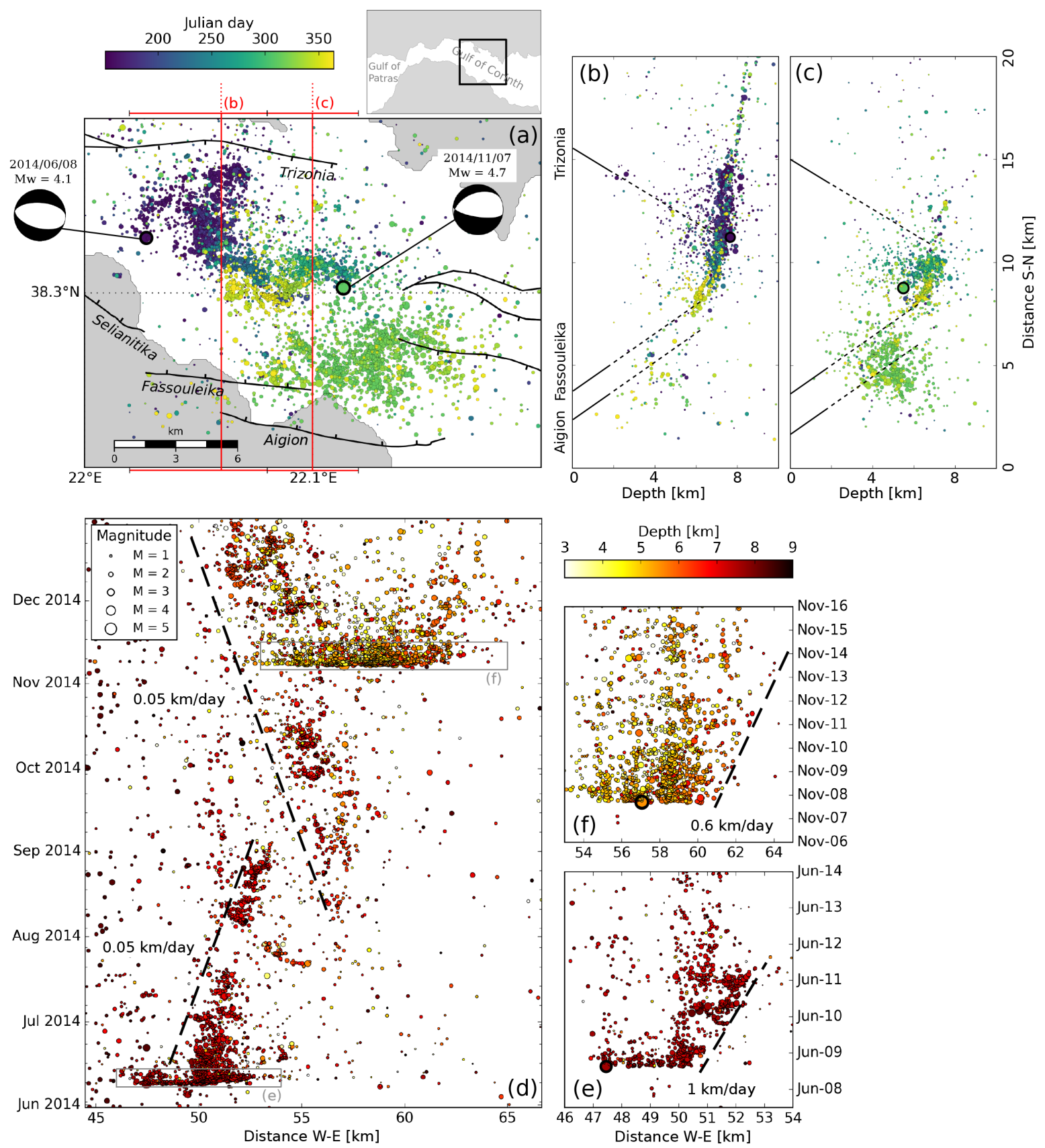

Figure 7. Seismic migration velocities during the western (ZW) swarm in 2014. (a) Map of the seismicity migration along the Selianitika-Fassouleika-Aigion fault system. The longitude $21.6^{\circ}$ is $0 \mathrm{~km}$ distance. Black lines are the main normal faults. The colourbar represents the time in Julian days of 2014 . Focal mechanisms are from NOA (National Observatory of Athens, 1997). Red lines delineate the two cross-sections displayed in (b) and (c) with their lateral extent. (b) N-S cross-section of the events occurring at the beginning of the crisis. (c) N-S cross-section parallel to the first one, further east, of the events occurring later during the crisis. (d) Temporal evolution of the microseismicity along the longitude. Circle size is proportional to the event magnitude. (e) and (f) are zooms in specific migrations, represented by light grey frames in (d). Black lines represent the main migrations seen with the corresponding velocities in km $\mathrm{d}^{-1}$. The colourbar represents the event depth.

Almost all the multiplets in the $\mathrm{ZC}$ and along the $\mathrm{TZ}$ belong to the long-term ones, that supports Godano et al. (2015)' observations. Multiplets in the IZ, as well as the ones located at the border of the silent patch between the Mornos fault and the Marathias fault, are also long-term multiplets. On the other hand, the short-term or bursttype multiplets appear only once and do not activate again later, even during other swarms in the same area. In the AFZ, multiplets mainly belong to this burst-type. They last less than $1 \mathrm{yr}$ and often occur during seismic crises or during aftershock sequences with no further reactivation during next swarms. Furthermore, on cross-sections of Fig. 9, we can see that long-term multiplets are systematically deeper than the short-term ones.

To complete this temporal analysis, we computed the interevent times $t_{r}$ inside each repeater to characterize the recurrence of repeater-events (Fig. 10). We remind that repeaters have been extracted using a similarity threshold $S_{c}=0.9$ for a $5 \mathrm{~s}$ window encompassing the $P$ and $S$ waves together. 30 per cent of events from the database and 45 per cent of multiplet events are inside repeaters. 

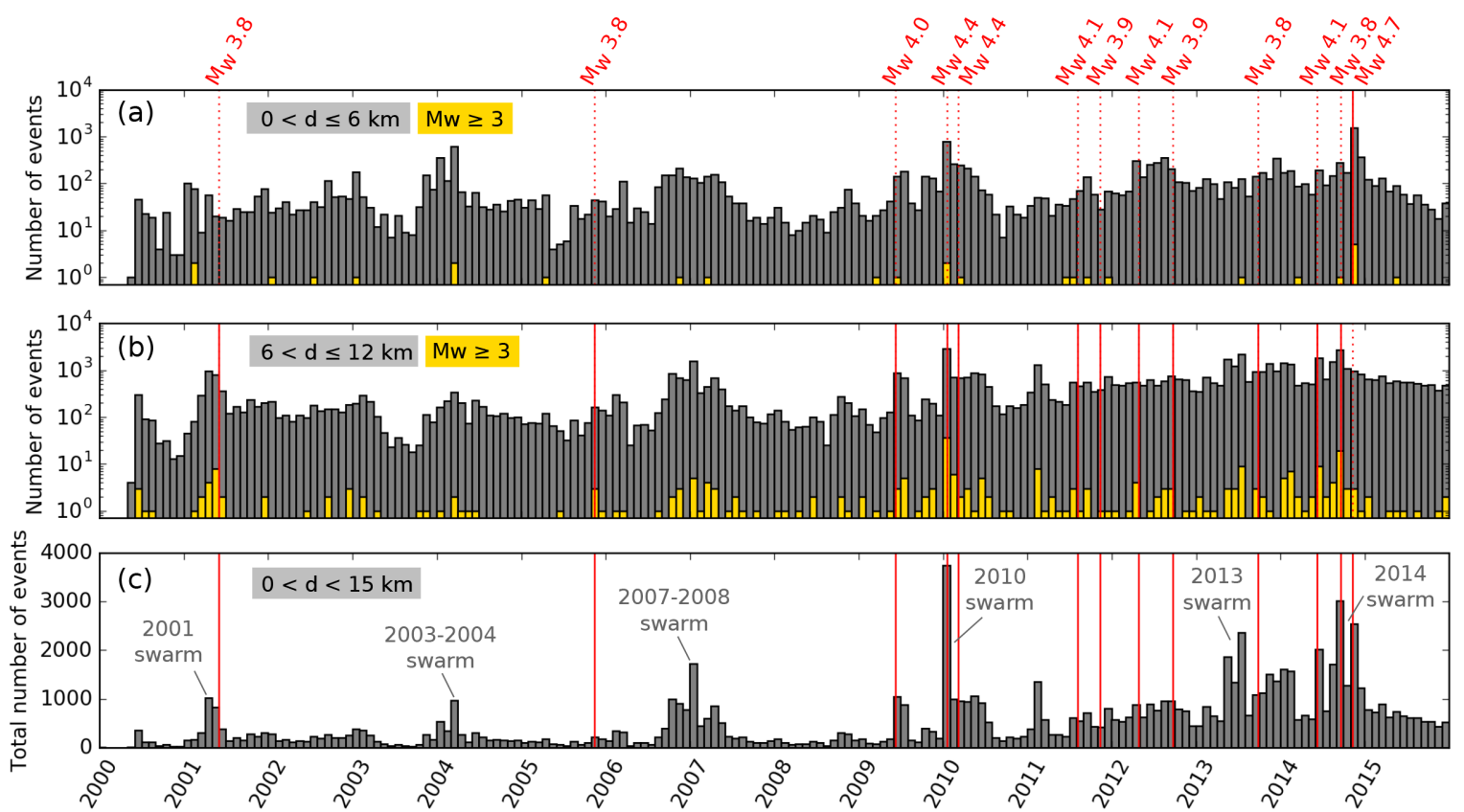

Figure 8. Histograms of seismic activity in time at different depth ranges. (a) Histogram of the number (in log scale) of superficial events ( $0 \leq$ depth $\leq 6 \mathrm{~km})$ through time. (b) Histogram of the number (in log scale) of deeper events $\left(6 \leq\right.$ depth $\leq 12 \mathrm{~km}$ ). Yellow histograms correspond to events of $M_{\mathrm{W}} \geq 3.0$. Vertical red lines indicate the occurrence time of the largest events $\left(M_{\mathrm{W}} \geq 3.8\right)$. The line is plain if the event occurred at the corresponding depth range, it is dashed otherwise. (c) Histogram of the total number of CRL events in the first $15 \mathrm{~km}$ depth. Main swarms are indicated in grey. Time bins are computed every month. The CRL network was enlarged in 2010, which explains the increase of the number of events from this year.

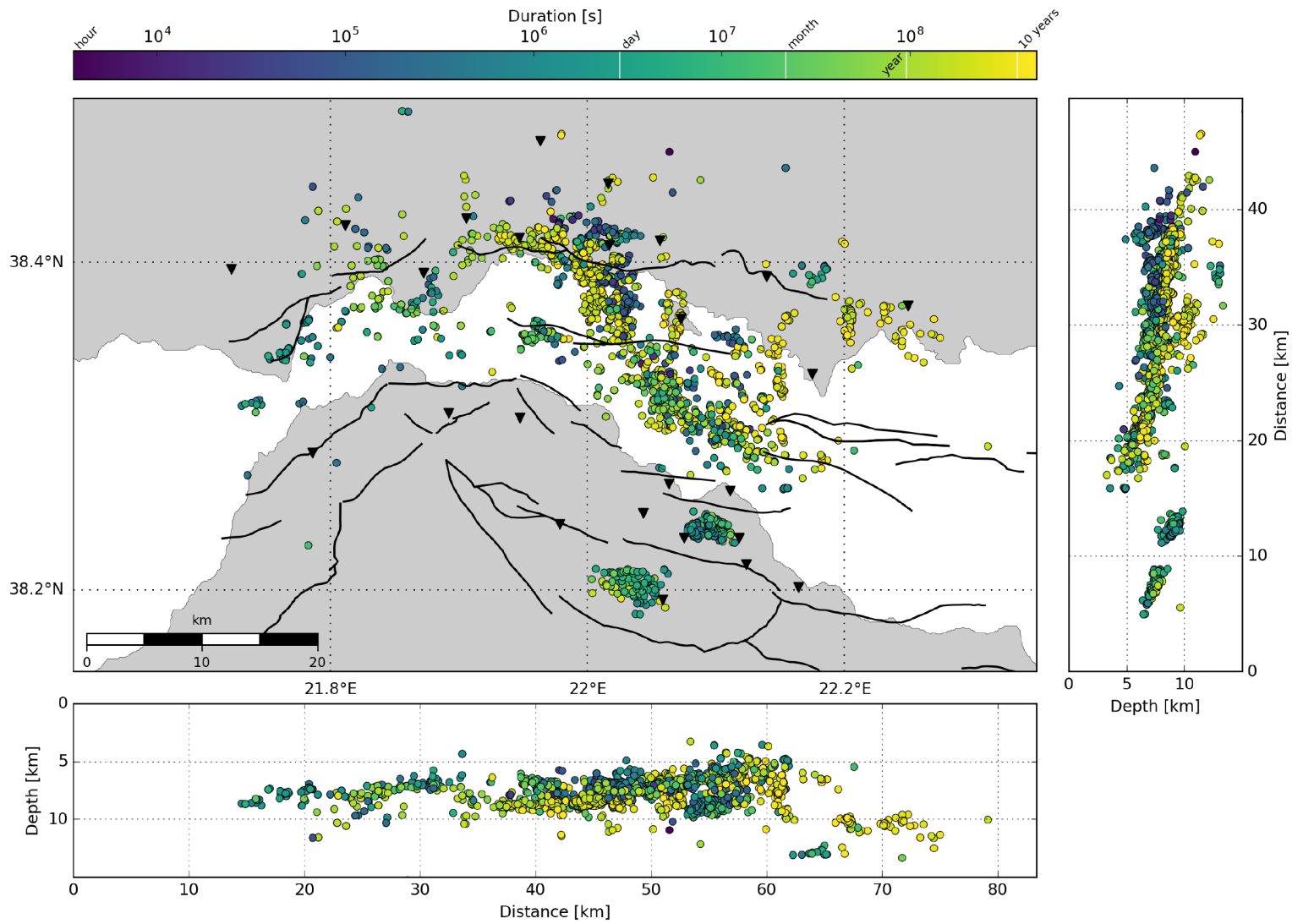

Figure 9. Maps of the multiplets. Each circle represents a multiplet having more than 10 events, which is located at the mean hypocentral position of its relocated events. Colours represent the duration (in seconds) of multiplets in log scale. White vertical lines in the colourbar indicate several temporal points of reference: $1 \mathrm{hr}, 1 \mathrm{~d}, 1$ month, $1 \mathrm{yr}$ and $10 \mathrm{yr}$. The same map with colours corresponding to the number of events per multiplet is in Supplementary Information Fig. SC.3. 

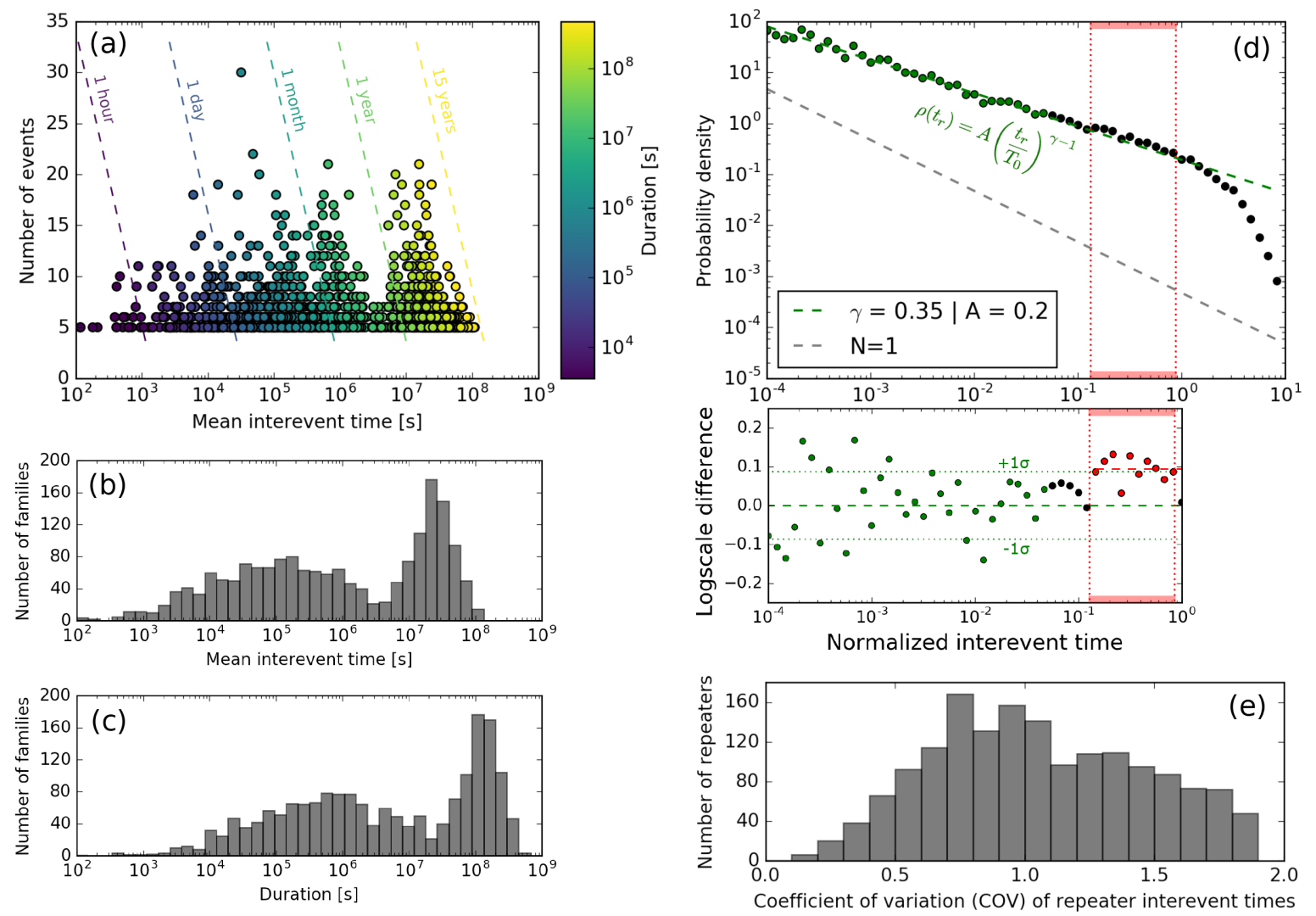

Figure 10. Analysis of the interevent times of repeaters with at least five events. (a) Number of events as a function of the mean interevent time $T_{0}$ (in seconds) of repeaters. Colourbar corresponds to the duration (in seconds) of repeaters in log scale. Coloured dashed lines are constant duration. Repeaters with small interevent times $\left(t_{r} \leq 2 \mathrm{hr}\right)$ never last long and never have a large number of events. (b) Histogram of repeaters' mean interevent time (in seconds). (c) Histogram of repeaters' duration (in seconds). (d) Stacked probability densities of normalized interevent times $\left(t_{r} / T_{0}\right)$ for repeaters. Green dashed line is the fitted $t_{r} / T_{0}$ gamma-law decay estimated thanks to the smallest normalized interevent times (green dots). Grey dashed line represents the number of samples equal to 1. The further we are from this line, the better the results are since more observations are included in the estimation. We plotted the differences between data and the regressed law in log scale and we estimated the standard deviation (dotted green lines) of the data to the law. Red dots highlight a small bump just above $1 \sigma$ for $10^{-1}<t_{r} / T_{0}<10^{0}$, corresponding to some quasi-periodic events. (e) Histogram depicting the coefficient of variation $(\mathrm{COV})$ distribution of repeaters.

For the presentation of the results, we only kept repeaters with at least five relocated events (Fig. 11). It represents more than 1000 families. We used the periodicity definition of Lengliné \& Marsan (2009) and computed the mean interevent time $\left(T_{0}\right)$ as the mean of the time intervals between successive events of a repeater.

Long-term repeaters have higher mean interevent times than short-term repeaters (Fig. 10a). For a same number of events per family, this relation is trivial but in the general case, it is not. The important feature is the dispersion of the interevent times for a given number of events per repeater. We observe a lack of large repeaters ( $N \geq 10$ events) with low mean interevent time $\left(T_{0} \leq 2 \mathrm{hr}\right)$.

The bimodal distribution of the repeaters' mean interevent time and duration (Figs 10b-c) is likely associated to their spatial location. The hole in the distribution at around respectively 2 months for interevent time and 8 months for duration, is probably a signature of the return period of a swarm in the same area. A swarm tends to last some months, but is never active more than 8 months. The time span of short-term repeaters is limited to the occurrence of specific seismic crisis, whereas long-term repeaters span over several swarms and periods of lower background seismicity, separated by several months, even years, in a same region.

For each repeater, we defined the normalized interevent times as $t_{r} / T_{0}$, which are then sorted by time bins over all families. To obtain a probability density, the number of recurrence times falling in each time bins is divided by the length of the time bin and by the total number of normalized interevent times. For this, we consider a gamma distribution:

$$
\rho\left(t_{r}\right)=A\left(\frac{t_{r}}{T_{0}}\right)^{\gamma-1} \exp \left(\frac{-t_{r}}{T_{0}}\right)
$$

where $A$ is a constant (Hainzl et al. 2006). If $\gamma=1$, then the seismic activity follows a Poisson law, that is, a random occurrence of events with no interactions (background seismicity). These events occur at a known mean frequency independently of the elapsed time since the previous event. On the other hand, if $\gamma=0$, the seismic activity follows an Omori law (Omori 1894) expressing the delayed interactions between a mechanical disturbance generated by an earthquake and the seismic rupture of the nearby faults. In other words, it characterizes the mainshock-aftershock sequences. Finally, if $0<\gamma<1$, then the seismic activity is clustered with a high number of events in a given time without particular interactions, and if $\gamma>1$, it follows a regular seismic cycle.

We represent the probability density function of the normalized interevent times and fitted the data by a gamma-law decay (Fig. 10d). We find $\gamma \approx 0.35$, typical of cluster activity, and observed a decrease similar to an Omori-law decay. We also note a really small bump 

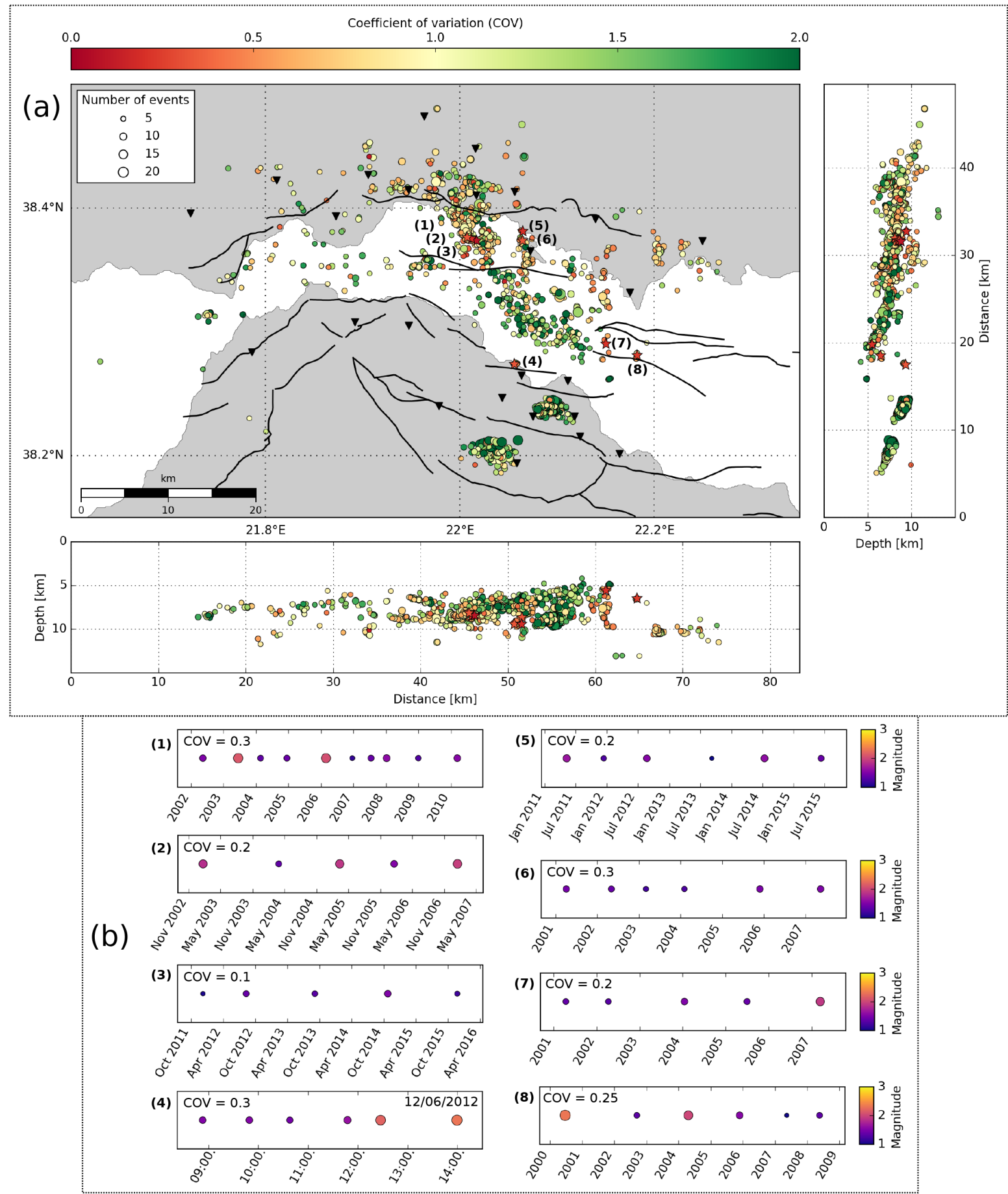

Figure 11. Periodicity of repeaters. (a) Map and north-south, east-west cross-sections of repeaters having more than five events. Each circle represents a repeater, which is located at the mean hypocentre position of its relocated events. The circle size is proportional to the number of events in the repeater. The colours indicate the coefficient of variation $(\mathrm{COV})$ of the interevent times for each repeater. A $C O V$ equal to 0 means that the repeater is fully periodic. A $\mathrm{COV}$ equal to 1 means that the repeater interevent times are random. A larger $\mathrm{COV}$ corresponds to repeaters having some much longer and some much shorter interevent times than its mean interevent time. (b) Temporal occurrences of events of some quasi-periodic repeaters. The colour and the size of circles are proportional to the event magnitude. These particular repeaters are identified by stars and numbers on the map and cross-sections.

between $10^{-1}$ and $10^{0} \mathrm{~s}$ with a factor of $\sim 1.25(0.1$ in log scale difference) compared to the linear log-log decay. The dynamics of earthquakes seems then dominated by interactions between asperities rather than steady stress accumulation on a single asperity. We can distinguish three different regimes: (1) about 65 per cent of the events are in clusters (temporal interactions between events of
Omori-type), (2) less than 35 per cent follows a Poisson law (random background seismicity) and (3) the remaining events occur quasi-periodically (red frame in Fig. 10d).

We further investigate the data in order to potentially identify the periodic or quasi-periodic earthquake recurrences, typical of repeater behaviour. To do so, we compute coefficients of variation 
$(\mathrm{COV})$ as the standard deviation of the interevent times divided by the mean interevent time by repeater. A $\mathrm{COV}$ of 0 implies a perfectly periodic recurrence, whereas a $\mathrm{COV}$ of 1 is characteristic of a Poisson sequence. The majority of $\mathrm{COV}$ values are between 0.5 and 1 (Fig. 10e). This is consistent with the fitted gammalaw decay seen in the probability density function. However, few repeaters show a very low $\mathrm{COV}$ value, which is expected in case of periodicity. We then plot some sequences of these repeating events in Fig. 11. A concern about distributions of interevent times is that chances are that some otherwise similar events may actually be missing (not detected/located) or not included in a repeater due to the strict criteria for waveform similarity. Neverthless, this repeating behaviour can be interpreted as the result of a constant stressing rate acting on the asperities (Lengliné \& Marsan 2009) and could suggest aseismic slip. The families last generally several years, but we also observed one example of a really short-term repeater, lasting less than half a day with a $\mathrm{COV}$ equal to 0.2 . Nevertheless, low $\mathrm{COV}-$ value repeaters correspond mainly to the long-term repeaters. They are concentrated in the same zones as seen before, that is to say the ZC, along the TZ and the IZ, and around the patch with no seismicity between the Mornos and the Marathias faults. On the other hand, the AFZ concentrates many high $\mathrm{COV}$-value repeaters, as well as the 2001-cluster and the 2013-cluster further south.

The events of repeaters should have similar moment magnitudes, and there must exist a relation between the mean recurrence time and the mean moment of a repeating sequence. To test this assumption, we computed the mean moment magnitude $\overline{M_{0}}$ of each repeater and compared it with its mean recurrence time $T_{0}$. For the whole repeater population (Fig. 12a), no trend was highlighted and long interevent times spread over the same magnitude range as the short ones. However, by selecting the most periodic repeaters $(\mathrm{COV}<0.6)$, we show that they primarily have large $T_{0}$ and that these repeaters with large $T_{0}$ seem to follow a linear relationship as Nadeau \& Johnson (1998)'s one (Fig. 12b). However, the magnitude range explored in our case is very narrow (only one order of magnitude) and too small to push further the interpretation in terms of mechanism.

We also tested two classical models of seismic hazard: (1) the time-predictable model, for which the rupture threshold is known but not the stress drop and (2) the slip predictable model, for which the stress drop is known, not the rupture threshold. For consecutive events of a repeater, we compared then either the magnitude of the first event to the interevent time or the magnitude of the second event to the same interevent time (Supplementary Information Fig. SC.4). However, no valuable information has been emphasized from these tests. We thus constrain this analysis for only the quasi-periodic repeaters $(\mathrm{COV} \leq 0.4)$. This sub-group of repeaters reflects the magnitude distribution of the whole repeater population but not the interevent time distribution. Recurrence times of the quasi-periodic repeaters are large, 70 per cent of them are larger than $10^{7} \mathrm{~s}$, that is, $\sim 4$ months. Moreover, for this population of large interevent times, we observe a trend consisting in an increase of the delays with an increase of the magnitudes of either the first or second event. This population is probably composed of real repeaters in the sense that a same asperity breaks, more or less regularly.

\section{DISCUSSION}

The relocation of this large data set of more than 200000 earthquakes was challenging because of the intense computational task required for the analysis of waveforms and parametric data. To accomplish the processing, we had to make choices such as dividing the region in several areas, deciding the distance threshold for crosscorrelations, determining damping values for the double-difference relocations and selecting a dissimilarity cut-off for multiplet classification. Although our results could probably be improved by studying limited areas individually Pacchiani \& Lyon-Caen (2010); Duverger et al. (2015); Kapetanidis et al. (2015) and by optimizing configuration parameters for each processing step, the results of this study provide a uniform view across the whole western Corinth Rift. Thus, this new, precisely located catalogue of events can be used to analyse spatial and temporal seismicity patterns across the whole highly active ZW.

\subsection{Seismic activity along the southern fault systems}

\subsubsection{Active faults}

Our relocation shows that the southernmost faults (West and East Helike, Kerinitis, Pirgaki) produce some microseismicity mostly in their downdip continuation, despite the reduction of their slip rate related to the northward migration of fault activities (Goldsworthy \& Jackson 2001; Palyvos et al. 2005; Ford et al. 2013), which favours the activity of the younger Kamarai fault system (Aigion-Fassouleika-Selianitika-Lambiri), as inferred from geological (Flotté 2003) and GPS observations (Avallone et al. 2004). In particular, the 2001-swarm occurred on the Kerinitis faults (Pacchiani \& Lyon-Caen 2010; Lambotte et al. 2014), and the 2013swarm is likely to be associated to the Pirgaki fault (Kapetanidis et al. 2015), although both faults are supposed to be geologically inactive. This suggests that these deep swarms are driven by pore pressure transients, and not directly by the tectonic shear loading rate. The large extension rate of the rift may, however, play a role in keeping a high permeability in the faulted volume at the intersection between the fault roots and the brittle geological layer at depth.

Further west, some microseismicity is located in the footwall of the Rion-Patras fault, which could be either associated to the inland Kastrisi fault, or to a weak geological layer, possibly the Phyllades nappe beneath the Tripolitsa nappe (Fig. 1) outcropping north to the Rion sill on the northern coast, and $20 \mathrm{~km}$ to the south of Patras (Beckers et al. 2015).

\subsubsection{Driving mechanisms in the middle of the rift}

The seismicity is concentrated in $1-2 \mathrm{~km}$ thick active layer in the middle of the rift, containing numerous multiplets with a wide range of strikes and dips (Lambotte et al. 2014; Godano et al. 2015). This layer has a high variability of internal structures along the rift over short distances. The best-fit planar structure to this thick microseismic layer is a plane roughly oriented $\mathrm{N} 260^{\circ} \mathrm{E}$, dipping $5-10^{\circ} \mathrm{N}$.

Along the Kamarai fault system, characterized by a high concentration of burst-like multiplets, we systematically observe seismic migration velocities of the order of tens or hundreds metres per day during seismic swarms. This is for instance the case during the 2014-swarm which has shown two migrations at $0.05 \mathrm{~km} \mathrm{~d}^{-1}$ in between the aftershock sequences. This matches the observations and interpretations by Duverger et al. (2015) during the 2003-2004 seismic crisis, and the computed migration velocities compare with that of a pore pressure front diffusion (e.g. Chen et al. 2012).

On the Aigion fault, which roots into this seismically active layer at about $6 \mathrm{~km}$ depth, we detect a notable seismicity up to a depth ( $\sim 3 \mathrm{~km}$ ) shallower than previously observed (Lambotte et al. 2014). 
(a)

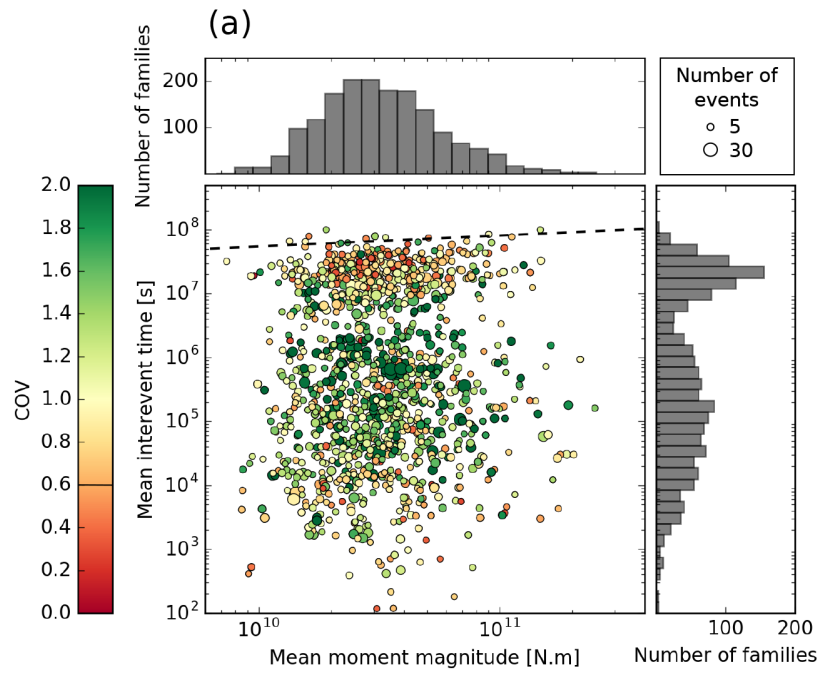

(b)

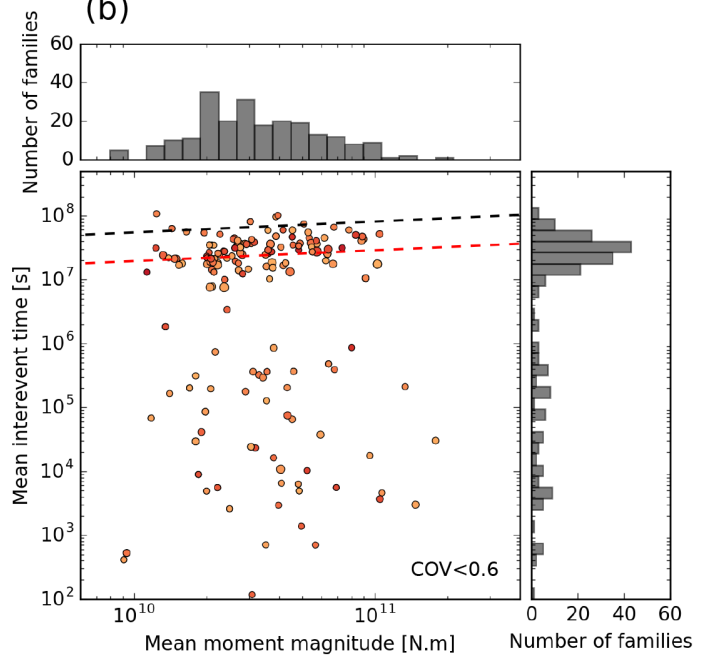

Figure 12. Variation of the mean recurrence time of a repeater as a function of the mean seismic moment of its events. (a) Graphs for all repeaters. Each circle corresponds to a repeater. Circle size is proportional to the number of events contained in the repeater. Colourbar refers to the repeater $\mathrm{COV}$. Black dashed line is the $\log \left(T_{0}\right)=4.85+0.17 \log \left(\overline{M_{0}}\right)$ relation reported by Nadeau \& Johnson (1998), where $T_{0}$ is the mean recurrence time in seconds and $\overline{M_{0}}$ is the mean seismic moment of the repeater in dyn $\mathrm{cm}\left(1 \mathrm{~N} \mathrm{~m}=10^{7}\right.$ dyn $\left.\mathrm{cm}\right)$. Histograms count the number of repeaters through mean moment magnitude bins (up), and mean interevent time bins (right). (b) is the same as (a) for a sub-population of more periodic repeaters ( $C O \mathrm{~V} \leq 0.6)$. Red dashed line illustrates a positive trend among repeaters with large interevent times and corresponds to the equation $\log \left(T_{0}\right)=4.4+0.17 \log \left(\overline{M_{0}}\right)$. Only the intercept differs from Nadeau \& Johnson (1998)'s relation.

It may indicate that the deeper part of the fault is continuously creeping over years while the upper part is partly locked, but can also partially creep, either continuously or episodically. This interpretation can be supported by InSAR observations (Elias 2013), which show creep on the Aigion fault with an uplift rate of about $2 \mathrm{~mm} \mathrm{yr}^{-1}$.

\subsubsection{Mechanics of short-lived repeaters}

In the middle of the gulf, along the Kamarai fault system, the asperities of repeaters are excited for a short time, usually during a single swarm, and then disappear, never break again. This phenomena could be interpreted as (1) a gradual abrasion of the roughness of the asperity leading to a loss of the seismic behaviour of the asperity, (2) the mechanical locking of the asperity, (3) the complete release of the available elastic energy and/or (4) the progressive alteration of the large scale rock mass resulting into a decorrelation of the waveforms.

The first hypothesis assumes that each repetitive rupture smooths the fault surface and reduces its friction, until it becomes aseismic and can slip continuously. This would imply a very speculative difference in the abrasion properties of these asperities with respect to those producing long-term repeaters.

The second hypothesis proposes a locking of the fault which may arise from a dislocation step cutting the fault surface due to slip on an intersecting fault. This seems plausible, as many small faults are expected to slip, seismically or aseismically, in the over-pressurized and sheared rock mass activated during a swarm episode.

The third hypothesis is based on the energy accumulation and release. An easy way to stop a multiplet activity is to reduce the local loading stress by the generation of a rather large slip, possibly aseismic, on a neighbouring fault, occurring during the swarm. But it is unlikely that such persistent stress shadow would systematically lock all short-term multiplets appearing in all swarms. Alternatively, the stored energy may be simply exhausted by the multiplet activity itself. In this case, the constant shearing rate due to the long-term tectonics, about $10^{-6} \mathrm{yr}^{-1}$, is too small to allow fast reloading in the duration of the swarm. Only slow slip around the asperities could amplify the local shear strain enough for allowing several seismic ruptures until reaching a total shear stress release. One might also consider an increase of the pore pressure leading to a decrease of the effective normal stress, which could trigger the rupture. In this case, five events with stress drop of about $1 \mathrm{MPa}$ would require an overpressure of $8 \mathrm{MPa}$ to be generated, assuming a friction coefficient of 0.6. Such high value is common in fluid injection experiments (e.g. Cornet et al. 1997), but probably not realistic for natural fluid pressure perturbations. The slow slip mechanism loading is thus the most likely dominant model under the hypothesis of exhaustion of the stored elastic energy.

The last hypothesis for the repeater disappearance is the possible decorrelation of the waveforms due to seismic velocity changes around the fault zone. The stress perturbations caused by the swarm activity have to be strong enough to sufficiently change the local velocity structure and significantly modify the waveforms generated by a single asperity. Moreover, the persistence of other repeaters from deeper zones imply that these modifications, if any, have to be limited to a few kilometres in the vicinity of the clusters, implying very large structural perturbations of the geological layer, which we believe are unlikely.

To conclude, the locking model and the exhaustion model assisted by slow slip are our preferred explanations for the short life of swarm-related repeaters. Note that in the case of non-repeater multiplets, that is, involving neighbouring rupture areas instead of a single asperity, the most likely explanation is the simple exhaustion model, as the locking model would require to separately operate on each of the neighbouring asperities.

\subsection{The 1995-fault rupture}

The observation of deep events at almost $15 \mathrm{~km}$ depth in the downdip continuation of the 1995 blind rupture plane could be interpreted as a longer fault extension at depth than previously established. The relatively sparse distribution of events deeper than $10 \mathrm{~km}$ may be 
related to a diffuse deformation zone and define a damage zone, consistent with an immature detachment proposed by Lambotte et al. (2014). However, as the seismicity reaches larger depths, it may provide evidence of a shear zone connecting to the fragileductile transition zone (Pham et al. 2000), which could make this detachment more efficient.

We also note that the seismicity rate downdip the 1995 rupture is constant since 2001, which is incompatible with the hypothesis of afterslip after the $1995, M_{\mathrm{W}} 6.3$ main shock. We thus propose that the observed deep microseismic activity is forced by the tectonic, shear loading in the detachment zone, which contributes to the present opening of the rift. This is further supported by the observation of persistent multiplets at these deep locations, with rather regular periodicity (low $\mathrm{COV}$, Fig. 11a), suggesting the existence of repeaters and thus the existence of large creeping subfaults (Igarashi et al. 2003) within the detachment. We find that persistent and rather regular multiplets also appear at shallower depth on the western edge of the 1995 rupture zone, again suggesting partial creep on the fault surface in their vicinity. However, the result by Godano et al. (2014) that one of these multiplets (\#866) was likely to be well isolated in a locked section suggests a strong heterogeneity of the friction and probably of the fault structure at this western fault edge. Moreover, this same multiplet \#866 was mechanically modelled by Dublanchet et al. (2015), who showed that the cluster of asperities should be located very close to an aseismically slipping fault segment to reproduce the dynamics of the sequence and the characteristics of the events.

\subsection{Seismicity gaps and the thin layer of seismicity}

\subsubsection{Lateral changes of seismicity rate}

The change in seismicity rate between the ZC and ZW marked by the TZ also coincides with a change in the rift geomorphology as already mentioned. In the ZW, the gulf is shallower and the bathymetry is marked by the Trizonia fault scarp (Beckers et al. 2015), whereas the ZC is deeper and marked by the Eratini and West Channel horsts (Bell et al. 2009). This change has been attributed to a difference in the geology of the basement (Taylor et al. 2011).

Two parallel structures (TZ and IZ) oriented north-south are illuminated by long-term and well-defined multiplets and some quasiperiodic repeaters, to the north of the thick seismically active layer. They are separated by $10 \mathrm{~km}$ of very low seismic activity and image a thinner layer $(\sim 0.2 \mathrm{~km})$, slightly dipping north with a dip of $15^{\circ}-$ $20^{\circ}$. They may delineate the border of a structural plane at depth, and the confinement of the multiplet and repeater activity at its edge may further indicate creeping surrounding a large, locked asperity.

Thanks to the westward extension of the network and the $15 \mathrm{yr}$ of seismic data, another seismic gap is revealed further west, between the Mornos and the Marathias faults. This gap is also surrounded by regular multiplets lasting several years, again suggesting creeping surrounding a large, locked asperity.

\subsubsection{Nature of the thin seismic layer}

The thin microseismic layer with seismic gaps highlighted above deserves more detailed analysis, as it may correspond to blind faults bordered by some asperities activated by creep, but also to a major geological interface. In order to investigate this question, we precisely identify this thin layer within 10 cross-sections (Supplementary Information Fig. SC.1d-m) across the rift, picking the depth of the upper and lower points delineating the layer. We image the surface in 3-D, materializing consecutive triangle planes between points (Fig.13a). We note different plane orientations, but to the first order we interpolated these points by a unique plane, minimizing the square of the sum of the vertical distances between the points and the plane. We obtain a surface with a strike angle of $\mathrm{N} 295^{\circ} \mathrm{E}$ and a dip angle of $10^{\circ} \mathrm{N}$. The maximum distance between a picked point and the best-fit plane is $0.7 \mathrm{~km}$ (Figs $13 \mathrm{~b}-\mathrm{c}$ ).

At a smaller scale, we can first identify a step in the depth between points located in the $\mathrm{ZC}$ and the $\mathrm{ZW}$. We then interpolate independently the four points from the $\mathrm{ZC}$ and the remaining points from the ZW. We find two planes quasi-parallel with similar strike angles $\left(\mathrm{N} 290^{\circ} \mathrm{E}\right)$ and dip angles $\left(10^{\circ} \mathrm{N}\right)$ separated by less than $1 \mathrm{~km}$ at depth.

We interpret this consistency over the rift length as the possible existence of a geological interface at depth. The vertical displacement of this surface could correspond to some limit within the nappes of the Hellenides at the TZ. In addition, we observe steep variations of triangle plane orientations around the mean interpolated plane at smaller scale, which could be assimilated to the roughness of the surface intersected by several faults with different orientations. We consider that this geological interface may behave as a faulting surface allowing large slip, as some of the nappes like the Phyllades one, may allow for a low friction coefficient to an interface, which would explain the existence and the characteristics of the microseismicity reported on it.

As the strike of the interpolated plane is similar to the strike of the old normal faults of the south coast (West Helike, Lakka), we do not reject the possibility that this rather planar surface acts as a major tectonic structure on which the faults root. The interpolated plane outcrops around $15 \mathrm{~km}$ south from the mapped Mamoussia fault (at the southern limit of our map). A possibility to make this plane connect with the southernmost faults at the surface would be with a large fault with a smaller dip angle at depth, which has already been observed for some major ancient faults on the southern coast with $10^{\circ}-15^{\circ}$ dip angle (Flotté et al. 2005).

\subsection{Connection between the Patras and the Corinth rifts}

We have described the along-strike change in the E-W evolution of the fault extension of the Kamarai fault system and the faults on either side of the Nafpaktos basin. In particular, we observe a $45^{\circ}$ change in strike between the Psathopyrgos fault and the Rion-Patras fault (an angle of $135^{\circ}$ between the two mapped fault extension). This raises some questions:

(1) how the connection at depth between these two faults is structured?

(2) do the faults slip independently or does the seismicity propagate along both planes continuously?

The refined analysis of the microseismicity results enable us to partly answer these questions. The first one is answered here but the second one is mainly discussed in the Section 4.5.

\subsubsection{Fault connection}

In section P19 (Fig. 5h), we have seen that the microseismicity occurring at $7 \mathrm{~km}$ depth on the Psathopyrgos fault plane is confined to the northward and downward mapping of the known surface fault, $12 \mathrm{~km}$ long and oriented E-W. The microseismicity goes deeper further west and the seismic layer gets thicker. The intersection at 
(a)

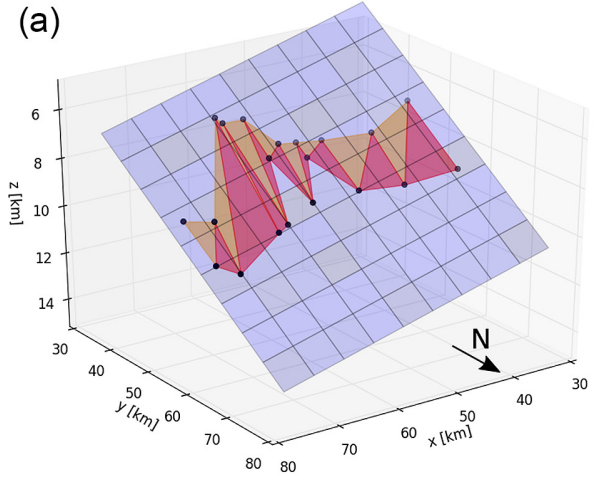

(b)

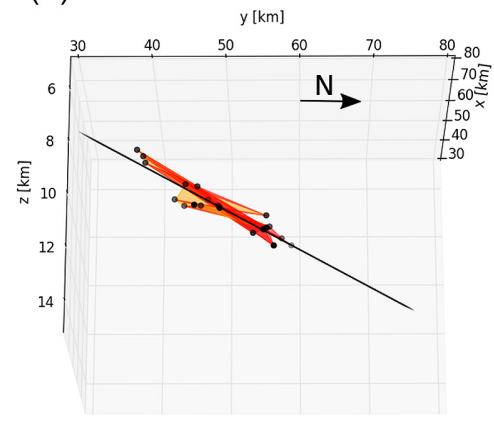

(c)

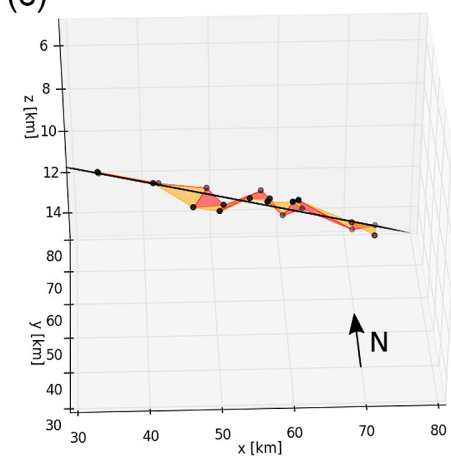

Figure 13. Interpolation of the thin layer of microseismicity. The black points correspond to the picked upper and lower depth of the thin microseismicity on 10 cross-sections (Supplementary Information Fig. SC.1 from P3 to P12). We reconstruct the layer surface by compiling the consecutive triangle surfaces (orange and red) between points. We interpolate these points by a 3-D plane, minimizing the square of the sum of vertical distances of the points to the plane. This plane is oriented $\mathrm{N} 295^{\circ} \mathrm{E} 10^{\circ} \mathrm{N}$. The vertical scale is exaggerated. (a)-(c) show three different views of the layer surface and the interpolated plane.

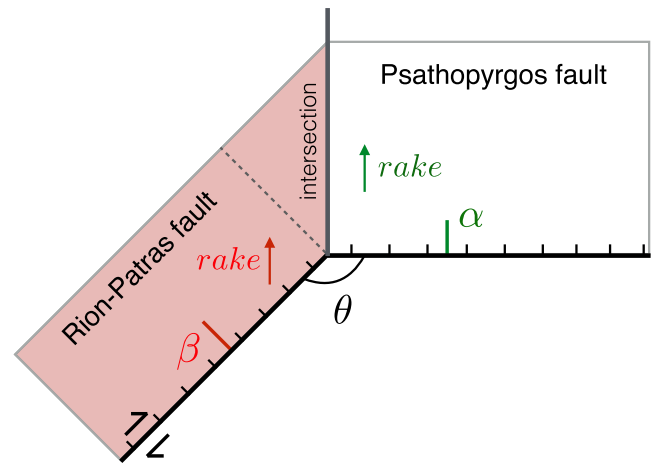

Figure 14. Geometry of the depth contact between the Psathopyrgos and the Rion-Patras faults. $\alpha$ is the dip angle of the Psathopyrgos fault. $\beta$ is the dip angle of the Rion-Patras fault. $\theta$ is the angle between the two fault traces at the surface $\left(\theta=135^{\circ}\right)$.

depth between the Psathopyrgos and the Rion-Patras fault planes thus could be drawn as a line in the north-south direction. The geometry of this contact then imposes a higher dip angle for the Rion-Patras fault (Fig. 14). Indeed, the relation between the dip angles of the two faults ( $\alpha$ for the Psathopyrgos fault and $\beta$ for the Rion-Patras fault), knowing the angle $\theta$ between the fault traces at the surface, is for this geometry:

$\tan (\beta)=\frac{1}{\cos (\theta) \tan \left(\frac{\pi}{2}+\alpha\right)}$.

Considering a dip angle $\alpha$ between $50^{\circ}-55^{\circ}$ for the Psathopyrgos fault, as observed at the surface, we obtain a dip angle $\beta$ between $59^{\circ}-64^{\circ}$ for the Rion-Patras fault, which is consistent with the microseismicity at depth. Such a steeper dip angle for the RionPatras fault also explains the deeper seismicity observed further west to the Psathopyrgos fault, at a same distance to the fault in section P19 (Fig. 5h). Moreover the fact that the edge delineating the intersection at depth between the two faults is oriented northsouth is compatible with the slip of the hanging wall on its footwall without internal deformation, and the oblique slip rake of the RionPatras fault.

The strike-slip component of the fault has been suggested by several authors from different types of data (e.g. Rigo et al. 1996; Hatzfeld et al. 2000; Parcharidis et al. 2011; Elias 2013; Beckers
2015). Indeed, from microseismicity analyses, Rigo et al. (1996) and Hatzfeld et al. (2000) documented pure strike-slip and obliqueslip earthquake focal mechanisms in the Nafpaktos Basin, between the Rion-Patras fault and the Nafpaktos fault on the northern coast. Beckers et al. (2015) showed for the first time evidence of strike-slip movements on offshore faults in the same area thanks to seismic acquisition, and finally InSAR data suggested that the Rion-Patras fault is creeping with about $4 \mathrm{~mm} \mathrm{yr}^{-1}$ normal slip and some rightlateral motion (Elias 2013; Parcharidis et al. 2011). Furthermore, the strongest earthquake in the area was the $1993 M_{\mathrm{W}} 5.4$ Patras earthquake, which showed a dextral slip with a dip-slip component (Papazachos \& Papazachou 1997; Hatzfeld et al. 2000; Flotté et al. 2005). However, this earthquake has been attributed to the Saravali fault, a parallel and further south fault than the RPZ.

Despite these observations, there is no published estimate of the slip partitioning between normal-slip and strike-slip mechanism. Our inferred geometry of contact between the Psathopyrgos fault and the Rion-Patras fault allows a first quantification of this partition, assuming no deformation in the hanging wall or the footwall. Indeed, in order to have a mechanically compatible slip (no creation of empty space when the fault blocks are moving) with the Psathopyrgos fault, the slip vector of the Rion-Patras fault, should be parallel to the one of the Psathopyrgos fault, whose horizontal component is oriented north-south. In this geometrical configuration, the Rion-Patras rake angle $(\lambda)$ is defined as

$\lambda=-\arccos \left(\frac{\sin (\alpha)}{\sin (\beta)}\right)-90^{\circ}$.

We obtained a rake angle ${ }^{2}$ of $-115^{\circ}$, which gives about 70 per cent of normal slip against 30 per cent of right lateral strikeslip.

\subsubsection{Long-term temporal evolution of the fault systems}

In terms of long-term evolution of the fault system, the northward migration of the deformation accommodation from old, inland southern faults to the presently active coastal southern faults

${ }^{2}$ Convention on rake angle: left-lateral strike slip: $0^{\circ}$, right-lateral strike-slip: $180^{\circ}$, normal slip: $-90^{\circ}$, reverse slip: $90^{\circ}$ 


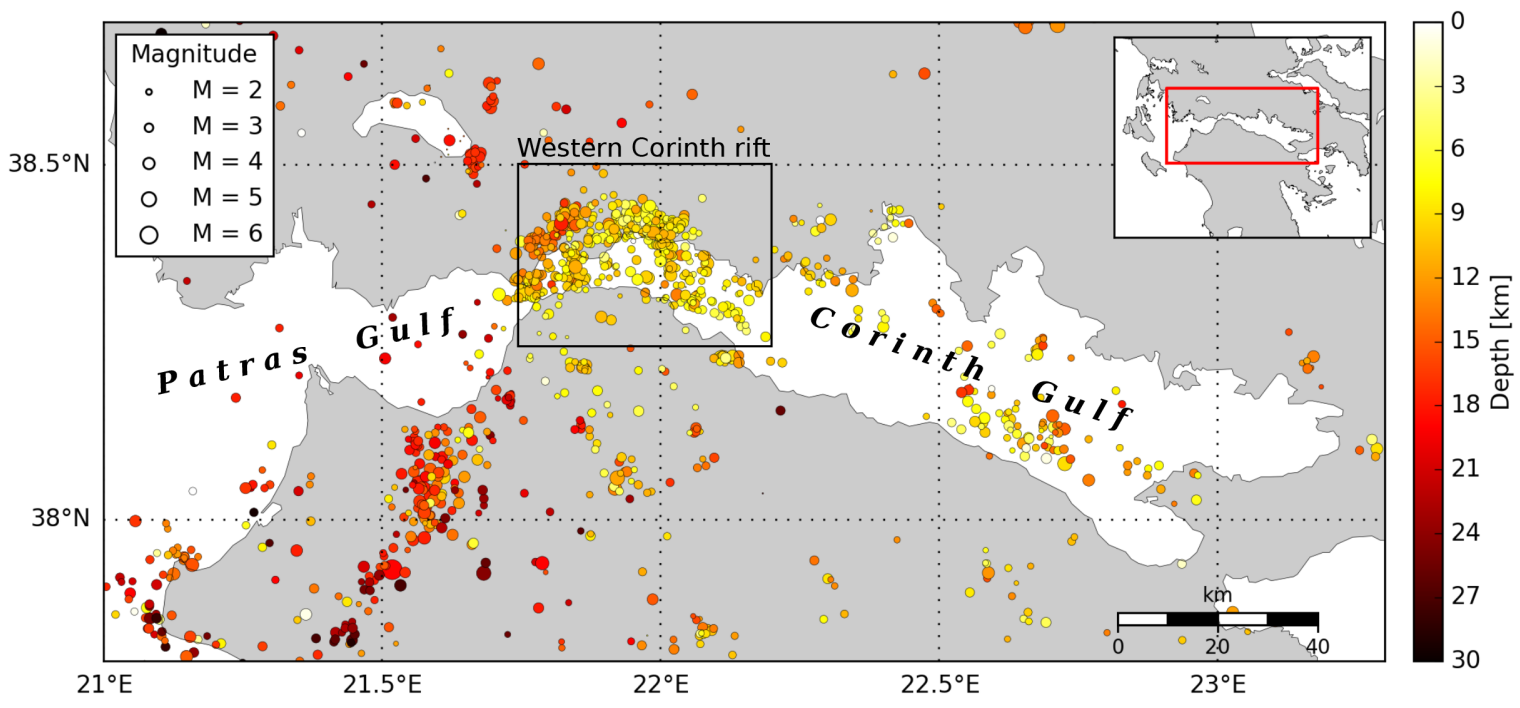

Figure 15. Map of the seismicity recorded by the NOA network (1997) in the Patras Gulf and the Corinth Gulf. Magnitude $M>2$ earthquakes from 2006 to 2015 are shown. The colours represent the event depths.

(Goldsworthy \& Jackson 2001; Palyvos et al. 2005; Ford et al. 2013) caused a $25 \mathrm{~km}$ northward shift of the depocentre of the Corinth Rift, and an NE-SW strike-slip motion connecting the Patras and the Corinth gulfs. The formation of these dextral trending transfer-faults started $0.9 \mathrm{Ma}$ (Flotté et al. 2005), with the activity of the Panachaikon faults. The initiation of the Psathopyrgos fault is estimated around $0.4 \mathrm{Ma}$, followed by the successive propagation towards the E-SE of normal faults of the Kamarai fault system on the southern coastline (Ford et al. 2016). The right lateral strike-slip activity of the West Panachaikon fault then migrated towards the NW, taken over by the Rion-Patras fault around $0.2 \mathrm{Ma}$ (Flotté et al. 2005), and catching up the Psathopyrgos fault system.

This evolution of the Rion-Patras-Psathopyrgos fault system is compatible with the proposed geometry of the faults inferred from our analysis. Indeed, thanks to analogue experiments, Schlagenhauf et al. (2008) showed that normal fault growth is expected to start with a rapid lateral lengthening in a short-term period, followed by a longer phase of slip accumulation with almost no lengthening. The length of Psathopyrgos fault was thus already defined and a priori stable when the Rion-Patras joined the fault system. Consequently, the Rion-Patras fault, with its dip angle and oblique slip rake, had to grow further towards the N-NE in order to reach, at all depths, the Psathopyrgos fault, avoiding the creation of a large volume of diffuse deformation at the fault intersection.

We finally note here that the microseismicity rate in the Patras rift is very low, as for the eastern part of the Corinth Rift (Fig. 15), despite the reported large strain rate all along the two rifts. Almost the whole microseismicity activity is recorded in the western Corinth Rift, and reasons for this behaviour are still not well understood, related to a specific interplay between some rheological characteristics of some Hellenide thrust nappes, and fluid migration possibly originating in the subduction.

\subsection{Seismic hazard}

Constraining the size, geometry and the locking state of the major seismogenic faults is pre-requisite for a proper assessment of the local seismic hazard. Here, the relocated microseismicity allows us to define which faults are regularly active, triggered or silent. Furthermore, their geometries are now better constrained than previously published, and in particular the precise location of the seismicity should help modellers to define the root depth of the faults.

In terms of fault length, the seismicity patterns enable us to confirm the re-evaluated length of the Psathopyrgos fault $(12 \mathrm{~km})$ found by geological studies by Beckers et al. (2015). The intersection of the Psathopyrgos fault with the Rion-Patras fault is now better constrained, and imposes a well-defined proportion of oblique-normal mechanism for the Rion-Patras fault. Our findings of 70 per cent of normal component and 30 per cent of rightlateral strike-slip could be cross-checked with displacement rates inferred from InSAR and GPS data. Moreover, new realistic scenarios of dynamic rupture Durand et al. (2014) could be considered thanks to this geometrical link between the two faults, and we could test numerically if ruptures can propagate from one fault to another.

Seismic hazard related to the coastal faults has been studied by Chartier et al. (2017) and Boiselet (2014), who integrated the observation that the last major earthquakes in the ZW ruptured blind faults (i.e. Aigion 1995 earthquake; Bernard et al. 1997) or faults not identified as a major structure (i.e. Efpalio sequence; Sokos et al. 2012). The new seismic gaps revealed by our study, beneath the Trizonia island downdip to the Aigion fault, and downdip to the Psathopyrgos-Lambiri faults, both surrounded by some longlasting multiplets and repeaters, present similar geometrical and microseismic features to that of the locked rupture plane of the Aigion 1995 earthquake. They may thus mark the existence of blind faults (Fig. 16a) which could be the location of large, seismogenic asperities with a potential of future earthquakes with magnitudes reaching 6.

Quantifying the possible interseismic creep, the locking state and the future coseismic slip on each of these fault segments, for a better assessment of the seismic hazard, remains a challenge. We however believe that progress can be made in future studies, by associating the constraints from the mechanics of multiplets and repeaters which we discovered, with the kinematic constraints from GPS and InSAR, benefitting from the better defined fault geometries brought by our analysis. 

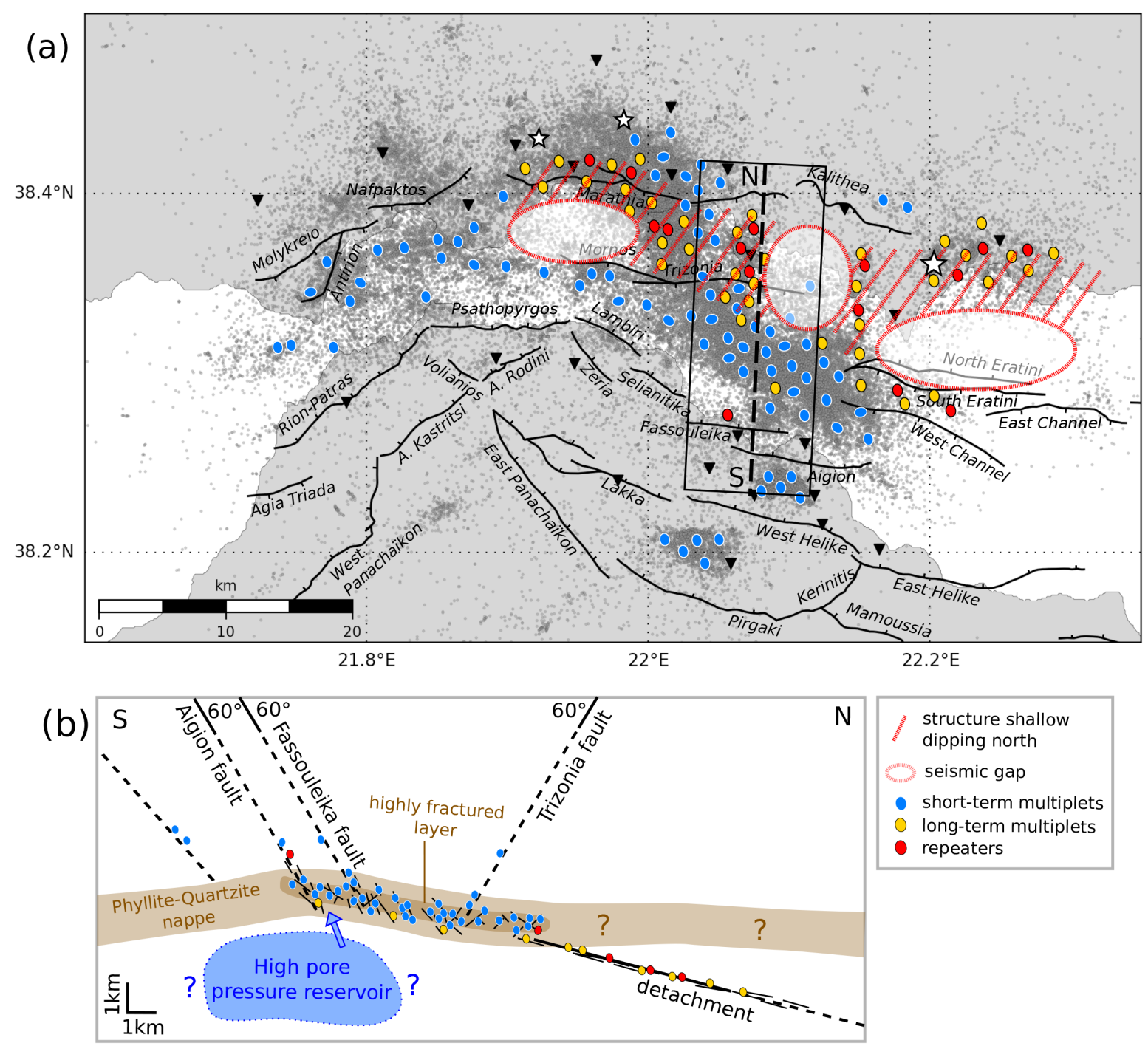

Figure 16. Interpreted mechanisms related to the seismicity. (a) Map of the relocated earthquakes (grey dots) with the main normal faults of the region (black lines) reported in Beckers (2015). Black triangles indicate the seismic stations. We schematically represent the short-lived multiplets (blue ellipses), the long-term multiplets (yellow ellipses) and the repeaters (red ellipses) in the cross-section area (black box). White transparent large ellipses locate the seismic gaps and potential blind faults. Zone with oblique red dashed lines corresponds to the projected thin structure shallow dipping north, interpreted as an immature detachment by Lambotte et al. (2014), and where long-term multiplets and repeaters occurred. (b) S-N cross-section showing the relation between the different earthquake multiplets and the structural and geological features at depth. Modified from Duverger et al. (2015).

\section{CONCLUSION}

The regional seismicity patterns in the western Corinth Rift have been highlighted thanks to the relocation of the micro-earthquake hypocentres, using a double-difference method. In detail, when compared to the former study of Lambotte et al. (2014), the spatial correlation between the dense microseismicity and active structures has been improved, the hypocentres become more thinly clustered at depth and families more sharply defined. The extension at depth of the known geometry of the fault planes at the surface is consistent with the spatial distribution of the microseismicity.

The detailed analysis of the spatio-temporal activity of multiplets and repeaters has highlighted strong spatial variation of family behaviour interpreted as different mechanical responses over the rift length. The zones beneath the gulf tend to generate many microearthquakes organized in intense but short-lived swarms, lasting weeks to months, which is interpreted as strong sensitivity of a specific geological layer to pore pressure variations and fluid circulations. To the contrary, the zones at the edges of former major rupture planes or presenting a low seismicity rate persistently generate highly correlated seismic events which repeat over long-term period, that is, several years (Fig. 16a). They are probably driven by slow aseismic slip occurring on patches of a large-scale, nearly planar weak surface, gently dipping to the north (Fig. 16b), which connects the central microseismic layer at $6-8 \mathrm{~km}$ in depth possibly down to the ductile middle crust.

We explored diverse aspects in terms of structures and mechanisms thanks to the relocated microseismicity and the event families. Our new, large multiplet database should allow for many more refined spatio-temporal studies, in particular systematically measuring and analysing migration velocities during swarms, in order to better understand the sources of the highly fluctuating seismicity rate. Moreover, GPS measurements and strainmeter data could be added to further support or discuss the mechanical models of 
the strain transients associated to these swarms, which needs more focused studies and was outside the scope of this study.

The present results show the importance of maintaining a permanent network of stations over several decades, which motivated the recent strategy followed by the Near Fault Observatory activity within the European Plate Observation System infrastructure (https://www.epos-ip.org).

For the future, our results strongly advocate for continuing the gathering and the analysis of seismic records together with geodetic data. The steady increase of the multiplet database and of the geodetic time-series, and their integrated analysis combining geometrical and kinematic aspects, should significantly improve their mechanical interpretations and modelling, allowing to better assess the seismic hazard in the region.

\section{ACKNOWLEDGEMENTS}

We sincerely thank Vassilis Kapetanidis for his constructive suggestions and numerous comments that substantially improved this manuscript, and one anonymous reviewer for its helpful remarks. Seismic data used in this study were collected by the CRL network (Corinth Rift Laboratory, http://crlab.eu). We strongly thank our colleagues Maurin Vidal (Géoazur) and El-Madani Aissaoui (IPGP) who participated in the maintenance of the network and all the members of the different institutions contributing to CRL, particularly from the University of Athens (Nikos Voulgaris, Panayotis Papadimitriou and Vasilis Kapetanidis), the University of Patras (Efthimios Sokos, Anna Serpetsidaki and Nikos Germenis), the Charles University in Prague (Jiri Zahradnik) and the National Observatory of Athens (Christos Evangelis). CRL has been supported in France by INSU CNRS and the Agence Nationale pour la Recherche through SISCOR project and by the European Community through REAKT project. Waveforms are freely distributed through European seismological data centres and event database will be made available through the EPOS facilities (RESIF, http://dx.doi.org/10.15778/RESIF.CL, and NOA, https://doi.org/10.7914/SN/HL). Numerical computations of crosscorrelations were performed on the S-CAPAD platform, IPGP, France, which is supported by the Ile-de-France region (via the SEASAME program), France-Grille and the CNRS MASTODONS program.

\section{REFERENCES}

Albini, P., Rovida, A., Scotti, O. \& Lyon-Caen, H., 2017. Large eighteenthnineteenth century earthquakes in western Gulf of Corinth with reappraised size and location, Bull. seism. Soc. Am., 107(4), 1663-1687.

Armijo, R., Meyer, B., King, G., Rigo, A. \& Papanastassiou, D., 1996. Quaternary evolution of the Corinth Rift and its implications for the Late Cenozoic evolution of the Aegean, Geophys. J. Int, 126(1), 11-53.

Avallone, A. et al. 2004. Analysis of eleven years of deformation measured by GPS in the Corinth Rift Laboratory area, C. R. Geosci., 336(4-5), 301-311.

Beckers, A., 2015. Late quaternary sedimentation in the western gulf of Corinth, $\mathrm{PhD}$ thesis, Grenoble Alpes, Université de Liège, Université Savoie Mont Blanc, pp. 192.

Beckers, A., Hubert-Ferrari, A., Beck, C., Bodeux, S., Tripsanas, E., Sakellariou, D. \& De Batist, M., 2015. Active faulting at the western tip of the Gulf of Corinth, Greece, from high-resolution seismic data, Mar. Geol., 360, 55-69.

Bell, R., McNeill, L., Bull, J. \& Henstock, T., 2008. Evolution of the offshore western Gulf of Corinth, Bull. geol. Soc. Am., 120(1-2), 156-178.
Bell, R., McNeill, L., Bull, J., Henstock, T., Collier, R. \& Leeder, M., 2009. Fault architecture, basin structure and evolution of the Gulf of Corinth Rift, central Greece, Basin Res., 21(6), 824-855.

Bernard, P., et al. 1997. The Ms = 6.2, June 15, 1995 Aigion earthquake (Greece): evidence for low angle normal faulting in the Corinth Rift, $J$. Seismol., 1(2), 131-150.

Bernard, P., et al. 2006. Seismicity, deformation and seismic hazard in the western rift of Corinth: new insights from the Corinth Rift Laboratory (CRL), Tectonophysics, 426(1-2), 7-30.

Boiselet, A., 2014. Cycle sismique et aléa sismique d'un réseau de failles actives: le cas du rift de Corinthe (Grèce), PhD thesis, École Normale Supérieure de Paris, Institut de Radioprotection et de Sureté Nucléaire.

Bourouis, S. \& Cornet, F., 2009. Microseismic activity and fluid fault interactions: some results from the Corinth Rift Laboratory (CRL), Greece, Geophys. J. Int., 178(1), 561-580.

Briole, P., et al. 2000. Active deformation of the Corinth rift, Greece: results from repeated Global Positioning System surveys between 1990 and 1995, J. geophys. Res., 105(B11), 25 605-25 625.

Chartier, T., Scotti, O., Lyon-Caen, H. \& Boiselet, A., 2017. Methodology for earthquake rupture rate estimates of fault networks: example for the western Corinth rift, Greece, Nat. Hazards Earth Syst. Sci., 17(10), 18571869.

Chen, X., Shearer, P. \& Abercrombie, R., 2012. Spatial migration of earthquakes within seismic clusters in Southern California: evidence for fluid diffusion, J. geophys. Res., 117(B4).

Cornet, F., Helm, J., Poitrenaud, H. \& Etchecopar, A., 1997. Seismic and aseismic slips induced by large-scale fluid injections, Pure appl. Geophys., 150(3-4), 563-583.

Cornet, F., Doan, M., Moretti, I. \& Borm, G., 2004. Drilling through the active Aigion Fault: the AIG10 well observatory, C. R. Geosci., 336(4-5), 395-406.

Dublanchet, P., Godano, M. \& Bernard, P., 2015. Inferring fault mechanical conditions from the source parameters of a complex microseismic multiplet in the Corinth rift, Greece, J. geophys. Res., 120(B11), 7655-7682.

Durand, V., Bouchon, M., Floyd, M., Theodulidis, N., Marsan, D., Karabulut, H. \& Schmittbuhl, J., 2014. Observation of the spread of slow deformation in Greece following the breakup of the slab, Geophys. Res. Lett., 41(20), $7129-7134$.

Duverger, C., Godano, M., Bernard, P., Lyon-Caen, H. \& Lambotte, S., 2015. The 2003-2004 seismic swarm in the western Corinth Rift: evidence for a multiscale pore pressure diffusion process along a permeable fault system, Geophys. Res. Lett., 42(18), 7374-7382.

Elias, P., 2013. Ground deformation observed in the western Corinth rift (Greece) by means of SAR interferometry, PhD thesis, École Normale Supérieure de Paris.

Flotté, N., 2003. Caractérisation structurale et cinématique d'un rift sur détachement : le rift de Corinthe-Patras, Grèce, $\mathrm{PhD}$ thesis, Université Paris XI, Orsay.

Flotté, N., Sorel, D., Müller, C. \& Tensi, J., 2005. Along strike changes in the structural evolution over a brittle detachment fault: example of the Pleistocene Corinth-Patras rift (Greece), Tectonophysics, 403(1), 77-94.

Ford, M., Williams, E., Malartre, F., Popescu, S.-M., Nichols, G., Williams, E. \& Paola, C., 2009. Stratigraphic architecture, sedimentology and structure of the Vouraikos Gilbert-type fan delta, Gulf of Corinth, Greece, in Sedimentary Processes, Environments and Basins, pp. 49-90, eds Nichols, G., Williams, E. \& Paola, C., International Association of Sedimentologists.

Ford, M., Rohais, S., Williams, E., Bourlange, S., Jousselin, D., Backert, N. \& Malartre, F., 2013. Tectono-sedimentary evolution of the western Corinth rift (central Greece), Basin Res., 25(1), 3-25.

Ford, M., Hemelsdaël, R., Mancini, M. \& Palyvos, N., 2016. Rift migration and lateral propagation: evolution of normal faults and sediment-routing systems of the western Corinth rift (Greece), Geol. Soc. Lond. Spec. Publ., 439.

Ganas, A., Chousianitis, K., Batsi, E., Kolligri, M., Agalos, A., Chouliaras, G. \& Makropoulos, K., 2013. The January 2010 Efpalion earthquakes (Gulf of Corinth, central Greece): earthquake interactions and blind normal faulting, J. Seismol., 17(2), 465-484. 
Gautier, S., Latorre, D., Virieux, J., Deschamps, A., Skarpelos, C., Sotiriou, A., Serpetsidaki, A. \& Tselentis, A., 2006. A new passive tomography of the Aigion area (Gulf of Corinth, Greece) from the 2002 data set, Pure appl. Geophys., 163(2-3), 431-453.

Ghisetti, F. \& Vezzani, L., 2004. Plio-Pleistocene sedimentation and fault segmentation in the Gulf of Corinth (Greece) controlled by inherited structural fabric, C. R. Geosci., 336(4), 243-249.

Godano, M., Deschamps, A., Lambotte, S., Lyon-Caen, H., Bernard, P. \& Pacchiani, F., 2014. Focal mechanisms of earthquake multiplets in the western part of the Corinth Rift (Greece): influence of the velocity model and constraints on the geometry of the active faults, Geophys. J. Int., 197(3), 1660-1680.

Godano, M., Bernard, P., Marsan, D. \& Dublanchet, P., 2015. Bayesian inversion of seismic spectral ratio for source scaling: application to a persistent multiplet in the western Corinth rift, J. geophys. Res., 120(11), 7683-7712.

Goldsworthy, M. \& Jackson, J., 2001. Migration of activity within normal fault systems: examples from the Quaternary of mainland Greece, $J$. Struct. Geol., 23(2), 489-506.

Got, J.-L., Fréchet, J. \& Klein, F., 1994. Deep fault plane geometry inferred from multiplet relative relocation beneath the south flank of Kilauea, $J$. geophys. Res., 99(B8), 15 375-15 386.

Hainzl, S., Scherbaum, F. \& Beauval, C., 2006. Estimating background activity based on interevent-time distribution, Bull. seism. Soc. Am., 96(1), 313-320.

Hatzfeld, D., Karakostas, V., Ziazia, M., Kassaras, I., Papadimitriou, E., Makropoulos, K., Voulgaris, N. \& Papaioannou, C., 2000. Microseismicity and faulting geometry in the Gulf of Corinth (Greece), Geophys. J. Int, 141(2), 438-456.

Hauksson, E. \& Shearer, P., 2005. Southern California hypocenter relocation with waveform cross-correlation, part 1: results using the doubledifference method, Bull. seism. Soc. Am., 95(3), 896-903.

Heezen, B., Ewing, M. \& Johnson, G., 1966. The Gulf of Corinth floor, Deep Sea Res. Oceanographic Abstr., 13, 381-411.

Igarashi, T., Matsuzawa, T. \& Hasegawa, A., 2003. Repeating earthquakes and interplate aseismic slip in the northeastern Japan subduction zone, $J$. geophys. Res., 108(B5).

Jolivet, L., Labrousse, L., Agard, P., Lacombe, O., Bailly, V., Lecomte, E., Mouthereau, F. \& Mehl, C., 2010. Rifting and shallow-dipping detachments, clues from the Corinth Rift and the Aegean, Tectonophysics, 483(3-4), 287-304.

Kapetanidis, V. et al. 2015. The 2013 earthquake swarm in Helike, Greece: seismic activity at the root of old normal faults, Geophys. J. Int, 202(3), 2044-2073.

Lambotte, S., et al. 2014. Reassessment of the rifting process in the western Corinth Rift from relocated seismicity, Geophys. J. Int, 197(3), 18221844.

Latorre, D., Virieux, J., Monfret, T., Monteiller, V., Vanorio, T., Got, J.L. \& Lyon-Caen, H., 2004. A new seismic tomography of Aigion area (Gulf of Corinth, Greece) from the 1991 data set, Geophys. J. Int, 159(3), 1013-1031.

Lee, W. \& Lahr, J., 1972. HYPO71: a computer program for determining hypocenter, magnitude, and RST motion pattern of local earthquakes, Open-File Rep, U.S. Geol. Surv., pp. 100.

Lengliné, O. \& Marsan, D., 2009. Inferring the coseismic and postseismic stress changes caused by the $2004 M_{\mathrm{W}}=6$ Parkfield earthquake from variations of recurrence times of microearthquakes, J. geophys. Res., 114(B10).

Lyon-Caen, H., Papadimitriou, P., Deschamps, A., Bernard, P., Makropoulos, K., Pacchiani, F. \& Patau, G., 2004. First results of the $\{$ CRLN $\}$ seismic network in the western Corinth Rift: evidence for old-fault reactivation, C. R. Geosci., 336(4-5), 343-351.

Mesimeri, M., Karakostas, V., Papadimitriou, E., Tsaklidis, G. \& Jacobs, K., 2017. Relocation of recent seismicity and seismotectonic properties in the Gulf of Corinth (Greece), Geophys. J. Int, 212(2), 1123-1142.

Moretti, I., Sakellariou, D., Lykousis, V. \& Micarelli, L., 2003. The Gulf of Corinth: an active half graben? J. Geodyn., 36(1-2), 323-340.
Nadeau, R. \& Johnson, L., 1998. Seismological studies at Parkfield VI: moment release rates and estimates of source parameters for small repeating earthquakes, Bull. seism. Soc. Am., 88(3), 790-814.

Omori, F., 1894. On after-shocks, Rep. Imp. Earthq. Inv. Corn., 2, 103-138.

Pacchiani, F. \& Lyon-Caen, H., 2010. Geometry and spatio-temporal evolution of the 2001 Agios Ioanis earthquake swarm (Corinth Rift, Greece), Geophys. J. Int., 180(1), 59-72.

Palyvos, N., Pantosti, D., De Martini, P., Lemeille, F., Sorel, D. \& Pavlopoulos, K., 2005. The Aigion-Neos Erineos coastal normal fault system (western Corinth Gulf Rift, Greece): geomorphological signature, recent earthquake history, and evolution, J. geophys. Res., 110(B9),

Palyvos, N., Lemeille, F., Sorel, D., Pantosti, D. \& Pavlopoulos, K., 2008. Geomorphic and biological indicators of paleoseismicity and Holocene uplift rate at a coastal normal fault footwall (western Corinth Gulf, Greece), Geomorphology, 96(1), 16-38.

Papazachos, B. \& Papazachou, C., 1997. The Earthquakes of Greece, Editions Ziti.

Parcharidis, I., Kourkouli, P., Karymbalis, E., Foumelis, M. \& Karathanassi, V., 2011. Time series synthetic aperture radar interferometry for ground deformation monitoring over a small scale tectonically active deltaic environment (Mornos, Central Greece), J. Coast. Res., 29(2), 325-338.

Pham, V., Bernard, P., Boyer, D., Chouliaras, G., Le Mouël, J. \& Stavrakakis, G., 2000. Electrical conductivity and crustal structure beneath the central Hellenides around the Gulf of Corinth (Greece) and their relationship with the seismotectonics, Geophys. J. Int, 142(3), 948-969.

Rietbrock, A., Tiberi, C., Scherbaum, F. \& Lyon-Caen, H., 1996. Seismic slip on a low angle normal fault in the Gulf of Corinth: evidence from high-resolution cluster analysis of microearthquakes, Geophys. Res. Lett., 23(14), 1871-1820.

Rigo, A., Lyon-Caen, H., Armijo, R., Deschamps, A., Hatzfeld, D., Makropoulos, K., Papadimitriou, P. \& Kassaras, I., 1996. A microseismic study in the western part of the Gulf of Corinth (Greece): implications for large-scale normal faulting mechanisms, Geophys. J. Int., 126(3), $663-688$

Rohais, S., 2007. Architecture stratigraphique et flux sédimentaires sur la marge sud du golfe de Corinthe (Grèce): analyse de terrain, modélisations expérimentales et numériques, $\mathrm{PhD}$ thesis, Université Rennes 1.

Satriano, C., Mejia Uquiche, A. \& Saurel, J.-M., 2016. Spectral estimation of seismic moment, corner frequency and radiated energy for earthquakes in the lesser antilles, in AGU Fall Meeting Abstracts, San Francisco, S13A-2518.

Schaff, D. \& Waldhauser, F., 2005. Waveform cross-correlation-based differential travel-time measurements at the Northern California Seismic Network, Bull. seism. Soc. Am., 95(6), 2446-2461.

Schaff, D., Bokelmann, G., Ellsworth, W., Zanzerkia, E., Waldhauser, F. \& Beroza, G., 2004. Optimizing correlation techniques for improved earthquake location, Bull. seism. Soc. Am., 94(2), 705-721.

Schlagenhauf, A., Manighetti, I., Malavieille, J. \& Dominguez, S., 2008. Incremental growth of normal faults: insights from a laser-equipped analog experiment, Earth planet. Sci. Lett., 273(3), 299-311.

Sokos, E., et al. 2012. The January 2010 Efpalio earthquake sequence in the western Corinth Gulf (Greece), Tectonophysics, 530, 299-309.

Stefanos, A., Papatheodorou, G., Ferentinos, G., Leeder, M. \& Collier, R., 2002. Seismic reflection imaging of active offshore faults in the Gulf of Corinth: their seismotectonic significance, Basin Res., 14(4), 487-502.

Taylor, B., Weiss, J., Goodliffe, A., Sachpazi, M., Laigle, M. \& Hirn, A., 2011. The structures, stratigraphy and evolution of the Gulf of Corinth rift, Greece, Geophys. J. Int, 185(3), 1189-1219.

Vita-Finzi, C., 1993. Evaluating late Quaternary uplift in Greece and Cyprus, Geol. Soc. Lond. Spec. Publ., 76(1), 417-424.

Waldhauser, F. \& Ellsworth, W., 2000. A double-difference earthquake location algorithm: method and application to the northern Hayward Fault, California, Bull. seism. Soc. Am., 90(6), 1353-1368.

Waldhauser, F. \& Schaff, D., 2008. Large-scale relocation of two decades of northern California seismicity using cross-correlation and doubledifference methods, J. geophys. Res., 113(B8).

Corinth Rift Laboratory team and RESIF Datacenter, 2013, CL - Corinth Rift Laboratory Seismological Network (CRLNET). RESIF - Réseau 
Sismologique et géodésique Français. Seismic Network., doi:10.15778/R ESIF.CL.

National Observatory of Athens, Institute of Geodynamics, Athens. , 1997. National Observatory of Athens Seismic Network. International Federation of Digital Seismograph Networks. Other/Seismic Network., doi:10.7914/SN/HL.

\section{SUPPORTING INFORMATION}

Supplementary data are available at $G J I$ online.

Figure SA.1. Logistic functions used to weight catalogue data. The signal-to-noise ratios of waveforms were reduced between 0 and 1 using a logistic function which is a sigmoid curve (see Supplementary Information eq. SE.1). The constants $L, k$ and $x_{0}$ were, respectively, set to $1,2.5$ and 3.0 for the manually picked data (green). The automatically picked data (red) were downweighted by increasing $x_{0}$ to 3.5 because of their poorer quality.

Figure SA.2. Density map of 16 yr seismicity in the western Corinth Rift and delimitation of zones for the relocation. (a) Map of the gulf of Corinth with coloured boxes, which indicate areas used to parallelize the relocation procedure. They have been designed taking into account the seismic density and are partially overlapping to ensure the spatial continuity in the seismicity for the relocation. (b) Spatial density map of epicentres $(n=115000)$ selected for the relocation process. The location of events is obtained with hypo 71 software. The grid resolution is $1 \times 1 \mathrm{~km}$. (c) Spatial density map of relocated epicentres $(n=94000)$ with hypoDD software. The grid resolution is $0.5 \times 0.5 \mathrm{~km}$. The colour represents the number of events per square-kilometre in log scale.

Figure SA.3. Similarity matrix and dendrogram. (a) This matrix contains similarity values for each event pair computed for events of two known multiplets from the 2003-2004 seismic crisis and random events from the CRL catalog. (b) The hierarchical clustering dendrogram computed from the matrix. This figurative tree shows a truncated dendrogram forming two distinct clusters (green and red) and isolating the remaining events (blue). The horizontal dashed line depicts the dissimilarity cut-off used $\left(D_{c}=0.32\right)$ to retrieve the known multiplets. The remaining events do not correlate (for the considered threshold) with other events.

Figure SA.4. Number of families created as a function of dendrogram truncation. Histograms of the number of multiplets (coloured) and doublets (shaded) for each zone as a function of the dissimilarity cut-off. The grey line stands for the percentage of doublets among multiplets. The different zone numbers are defined in Supplementary Information Fig. SA.2.

Figure SA.5. Synthetic case showing the influence of the delay between $P$ - and $S$-phase on cross-correlation coefficient $\left(C_{C}\right)$ and time-shift $\Delta t$. (a) $C_{C}$ as a function of the number of added samples between $P$ - and $S$-pick. (b) $\Delta t$ as a function of the number of added samples between $P$ - and $S$-pick. We used several original traces from the CRL data set as inputs and computed modified traces by adding random samples between $P$ - and $S$-pick (from 1 to 5 samples). Then we cross-correlated the original trace to the filtered modified one to retrieve a $C_{C}$ and a $\Delta t$. Red curves present the mean value of (a) $C_{C}$ and (b) $\Delta t$ for each number of added samples, with the standard deviation as error bars.

Figure SB.1. Percentage of cross-correlated events for $P$ - or $S$-wave windows. Histograms of number of events ( per cent) that correlate with at least another event in a $5 \mathrm{~km}$ radius, at cross-correlation thresholds ranged from 0.5 to 0.9 , for the $P$-wave train (black) and $S$-wave train (grey) at station (a) AGEO, (b) PSAR and (c) TRIZ. Histograms have been done for events of the zone05 (see
Supplementary Information Fig. SA.2). Stations ALIK and AGEO are on the southern coast whereas PSAR and TRIZ are on the northern coast. All considered events correlate with another event in a $5 \mathrm{~km}$ radius at a $C_{C}$ threshold of 0.6 for the $P$-phase.

Figure SB.2. Cross-correlation of noise windows. Histograms of $C_{C}$ estimated randomly on a thousand $1 \mathrm{~s}$ noise windows extracted on the vertical component before the $P$-phase arrival, for station (a) ALIK, (b) AGEO, (c) PSAR and (d) TRIZ. The mean $\mu$ and the standard deviation $\sigma$ of the best-fitting normal distribution (blue curve) are given for each station. $\mu *$ and $\sigma *$ are the parameters of the best-fitting log-normal distribution (black curve), given with the mode, which is the most representative value of the distribution. The average mean of $C_{C}$ fluctuates around 0.4 for CRL stations. Systematically, log-normal distributions better fit the data. (e) This graph represents survival functions, which give the probability for an observation to exceed a $C_{C_{\text {lim }}}$, computed for all stations of the CRL network. The survival function can be written as $S(x)=1$ - $\Phi(x)$, where $\Phi$ is the cumulative distribution function. In other words, to obtain the blue curve which corresponds to the data, we cumulatively sum the number of observations per bin in the histogram gathering all station observations, from the last bin to the first bin, divided by the total number of observations. The blue and black lines are respectively the best-fitting normal and log-normal survival functions.

Figure SB.3. Synthetic case showing the influence of signal-tonoise ratio (SNR) on cross-correlation coefficient $\left(C_{C}\right)$ and timeshift $\Delta t$. (a) $C_{C}$ as a function of SNR. (b) $\Delta t$ as a function of SNR. The colourbar corresponds to the reduced SNR introduced with the Supplementary Information eq. (SE.1). We used an original trace from the CRL data set as input (event occurred on 2003 November 17-00.26.17 and recorded at the station AGEO, showing a high $\mathrm{SNR}$ ). We computed a thousand noisy traces from the original one, by shifting it in time by a pre-set time lag of $\Delta t=0.12 \mathrm{~s}$ and by adding random white noise. They are filtered in the same frequency range as the original. Then we cross-correlated the original trace to each noisy trace to retrieve a $C_{C}$ and a $\Delta t$. The SNR values are estimated from the noisy traces. Red curves present the mean value of (a) $C_{C}$ and (b) $\Delta t$ for each SNR bin with the standard deviation as error bars.

Figure SB.4. Influence of the event separation distance $(\Delta)$ on cross-correlation coefficient $\left(C_{C}\right)$. The different curves are contours at different confidence levels (50, 75, 90 and 99 per cent). They are computed by dividing the $x$-axis into bins of equal number of data (1500 observations per bin), representing by each circle. The data are evaluated on the $P$-phase for station TRIZ, where the breakdown of the waveform similarity with increasing distance is well observed. Figure SB.5. Influence of the magnitude difference $\Delta M_{\mathrm{W}}$ on crosscorrelation coefficient $C_{C}$. Data are evaluated on the $P$-phase for the station DIMT. (a) The different curves are contours at different confidence levels $(50,75,90$ and 99 per cent). They are computed by dividing the $x$-axis into bins of equal number of data (1500 observations per bin), representing by each circle. Waveform similarity is slightly decreasing with increasing magnitude difference for $\Delta M_{\mathrm{W}} \geq 1$. (b) Data are limited to only pairs of events with a $C_{C} \geq 0.5$, in order to better observed the relation between $C_{C}$ and $\Delta M_{\mathrm{W}}$. Black curve represents the mean of $C_{C}$ computed by dividing the $x$-axis into bins of equal length $\delta\left(\Delta M_{\mathrm{W}}\right)=0.2$. Grey curve represents the normalized number of data taking into account to compute the mean of $C_{C}$ per bin.

Figure SC.1. Additional vertical cross-sections along the western Corinth Rift. The map location of these cross-sections are identified by rectangles in the main article, Supplementary Information Fig. 
S5(b). Profils with a red name " $P-$ " are also shown in the main article. Bold black lines indicate the major onshore and offshore faults. Light blue lines at the surface represent the offshore rift. The colour scale corresponds to the moment magnitude. Dark blue lines at panel bottom represent the extension of zones defined in Supplementary Information Fig. S5(a) and in the text (NEZ, North Eratini Zone; TZ, Transition Zone; IZ, Trizonia Island Zone; AFZ, Aigion-Fassouleika Fault Zone; 2AZ, Aftershock Zone of the 2010 doublet; RFZ, Rion-Patras Fault Zone). The black arrows in (a)-(c) are the location of the swelling at the transition zone (TZ). The white star in (e) is the location of the $M_{\mathrm{W}} 6.31995$ earthquake, and the white stars in (1) and (m) are the locations of the $M_{\mathrm{W}} 5.2$ and $M_{\mathrm{W}} 5.3$ of the 2010 earthquake doublet, respectively.

Figure SC.2. Histogram of event depths. Depth bins are computed every $0.5 \mathrm{~km}$ for $1.2 \leq M_{\mathrm{W}}<3$ events (in grey) and $M_{\mathrm{W}} \geq 3$ events (in black). The largest events are deeper than the remaining microseismicity.

Figure SC.3. Maps of the multiplets. Each circle represents a multiplet having more than 10 events, which is located at the mean hypocentral position of its relocated events. Colours indicate the number of events per multiplet. Colourbar is truncated at 30 events.
Figure SC4. Recurrence time data of repeaters versus simple seismic cycle models. (a) The interevent times of repeaters as a function of the magnitude of the first event (main shock). We investigated a possible dependency of the occurrence time of an event knowing the magnitude (stress drop) of the previous event. This is equivalent to the time-predictable model, for which a constant stress threshold is assumed. Each grey dots is for a couple of events. A coloured contour plot is added to better observe the pattern. (b) Same as (a) but the interevent times of repeaters is represented as a function of the magnitude of the second event (triggered). We investigated a possible dependency of the necessary time to trigger the future event knowing its magnitude (stress drop). This is equivalent to the slip-predictable model, for which a constant minimal stress is assumed. Finally, no dependency is observed here, our data do not follow simple seismic cycle models.

Please note: Oxford University Press is not responsible for the content or functionality of any supporting materials supplied by the authors. Any queries (other than missing material) should be directed to the corresponding author for the article. 